\title{
II. AUSGANGSLAGE IN DEN EINZELNEN TERRITORIEN
}

\section{Landständische Verfassung}

Je m'occupe sans relâche, teilte Prinz Murat Napoleon unmittelbar nach Übernahme der Herrschaft in Berg und Kleve am 31. März 1806 mit, à étudier l'administration du duché de Berg. C'est un cahos que j'ai beaucoup de peine à débrouiller. Il ne fut jamais d'organisation moins régulière que celle qui existait ici. Une portion des revenus appartenait au roi de Bavière, une portion au duc de Bavière son beau-frère; une portion était sensée appartenir au pays même, et affectée à un certain genre de dépenses; mais tout cela était géré sans aucun ordre. Il y avait une régence royale, une régence ducale, un conseil intime, une commission [...] personne n'avait d'attributions fixes ${ }^{1}$.

Was Murat für das Herzogtum Berg monierte, galt zugleich für viele dem Großherzogtum inkorporierten Territorien. Auch in diesen und ähnlich wie in anderen Gebieten des Alten Reiches ${ }^{2}$ stellte die innere Organisation beim Übergang der Herrschaft an den französischen Prinzen kein übersichtliches Ganzes dar, sondern war geprägt von widersprüchlichen Strukturen, undurchschaubaren Kompetenzzuweisungen und verworrenen Verwaltungsabläufen. Dieser Wirrwarr war nur bedingt auf die einschneidenden Umwälzungen zurückzuführen, von denen die deutsche Territoriallandschaft nach 1789 erfaßt wurde. Er stellte vielmehr in erster Linie das Ergebnis eines bis in das 17. Jahrhundert zurückreichenden Transformationsprozesses dar, in dessen Verlauf das altständische Verfassungsgefüge vermehrt durch landesherrliche Verwaltungselemente überlagert worden war. $\mathrm{Zu}$ den wesentlichen Bedingungsfaktoren dieser Entwicklung gehörten die mit den kriegerischen Auseinandersetzungen im 17. Jahrhundert gewachsenen Herrschaftsaufgaben in den einzelnen Territorien. Durch die große Schuldenlast, die die militärischen Konflikte verursacht hatten, wie auch die hohen finanziellen Aufwendungen, die für das stehende Heer zu leisten waren, gerieten die Monarchen in immer größere Bedrängnis und wurden schließlich dazu genötigt, die finanziellen Ressourcen ihrer Herrschaft auf feste Grundlagen zu stellen ${ }^{3}$. Parallel dazu intensivierte

1 Brief Joachim Murats an Napoleon vom 31. März 1806, abgedruckt in: Lettres et documents, Bd. 4, Nr. 2293, S.190f., Zitat S. 190.

2 Vgl. Dietmar Willowerr, Allgemeine Merkmale der Verwaltungsorganisation in den Territorien, in: Kurt G. A. Jeserich u. a. (Hg.), Deutsche Verwaltungsgeschichte, Bd.1: Vom Spätmittelalter bis zum Ende des Reiches, Stuttgart 1983, S.289-346; ferner TREICHEL, Primat, S.25f.

${ }^{3}$ Zur Rolle des Krieges bei der Herausbildung des modernen Staates allgemein: Wolfgang Reinhard, Das Wachstum der Staatsgewalt. Historische Reflexionen, in: Der Staat 31 (1992) 1, S. 58-75, hier S.67f.; zur Entwicklung der Staatsgewalt allgemein siehe DeRS., 
sich das Verwaltungshandeln, zumal sich mit den veränderten Herrschaftsaufgaben die Zuständigkeiten der Administration ohnehin erheblich ausdehnten. Da Organisation und Personal der bestehenden altständischen Behörden kaum dazu geeignet waren, die erweiterten Funktionen zu erledigen, kam es hierbei zu erheblichen Aus- und Umbaumaßnahmen innerhalb des altständischen Behördenapparats. Neue, den Landesherren verpflichtete Institutionen entstanden mit klaren Satzungen und festem Personal. Alte, in der genossenschaftlichen Herrschaftsstruktur verwurzelte Einrichtungen verloren ihre einstige Bedeutung oder gerieten unter landesherrliche Aufsicht und Kontrolle.

Dem Handlungsspielraum der Krone waren durch die korporativen Verfassungsstrukturen allerdings von vornherein gewisse Grenzen gesetzt, weil die Fürsten Entscheidungen, welche die innere Organisation betrafen, formal nur mit Zustimmung der mitspracheberechtigten Kräfte, allen voran des ritterbürtigen Adels, fällen konnten. Da die Monarchen aufgrund finanzpolitischer Zwänge weitgehend auf die Unterstützung der ständischen Vertretungsorgane angewiesen blieben - was insbesondere für die Herzogtümer Berg und Kleve sowie die Grafschaft Mark galt ${ }^{4}$-, mußten sie gegenüber den Ständen zwangsläufig oftmals einlenken und Konzessionen an die korporative Verfassung machen. Hinzu kam, daß sich die Ständekollegien häufig gegen die absolutistischen Bestrebungen ihrer Landesfürsten zur Wehr setzten und ihre Rechte bei den Reichsbehörden einklagten. Beträchtlichen Rückhalt fanden sie in diesem Zusammenhang bei der Reichsverfassung, deren Institutionen schützend von ihnen angerufen werden konnten, wenn angestammte ständische Rechte gefährdet waren ${ }^{5}$. Darüber hinaus mußten die Monarchen die Herrschaftsrechte der intermediären Gewalten auch akzeptieren, um keinen offenen Rechtsbruch zu begehen. Landesherrliche Eingriffe in die bestehende Rechtsordnung galten nämlich nach wie vor als unvereinbar mit dem vorherrschenden Verständnis von Verfassung als der Summe der überlieferten Rechtsverhältnisse und Gewohnheiten, d.h. als einem statischen Gebilde ${ }^{6}$.

Geschichte der Staatsgewalt. Eine vergleichende Verfassungsgeschichte Europas von den Anfängen bis zur Gegenwart, München 1999.

4 Engelbrecht, Herzogtum, S. 34, 87; Müller, Das Haus, S. 17; Rainer KuhNa, Die ständische Verfassung in den Westfälischen Landesteilen Preußens und im Fürstbistum Münster 1780-1806, Münster 1963, S.63f.; Helmuth CrooN, Stände und Steuern in Jülich-Berg im 17. und vornehmlich im 18. Jahrhundert, Bonn 1929, S.251.

5 Siehe Günther BIRTSCH, Die landständische Verfassung als Gegenstand der Forschung, in: Dietrich Gerhard (Hg.), Ständische Vertretungen in Europa im 17. und 18. Jahrhundert, Göttingen 1969, S.32-55, hier S.45f.; Volker Press, Landstände des 18. und Parlamente des 19. Jahrhunderts, in: Helmut Berding, Hans-Peter Ullmann (Hg.), Deutschland zwischen Revolution und Restauration, Königstein/Ts. 1981, S.133-157, hier S.134f.; ENGELBREChT, Herzogtum, S. 52, 87.

6 Dazu Dietmar Willowerr, Struktur und Funktion intermediärer Gewalten im Ancien Régime, in: Gesellschaftliche Strukturen als Verfassungsproblem. Intermediäre Gewalten, Assoziationen, Öffentliche Körperschaften im 18. und 19. Jahrhundert, Berlin 1978, S.9-27, hier S.17f. 
Das Wort »Verfassung « war ein »Seinsbegriff «7, besaß aber noch nicht, wie dies in Nordamerika und Frankreich der Fall war, normsetzenden Charakter. Jede Provinz verfügte demzufolge über eine ihr spezifische Rechtsordnung ${ }^{8}$, deren Bestand die Reichsverfassung schützte. Schließlich engten auch politische Notwendigkeiten das Ausgreifen der landesherrlichen Macht erheblich ein. Da das Gros der Provinzen zu auswärtigen Dynastien gehörte, hingen Stärke und Durchsetzungsvermögen der außer Landes residierenden Monarchen in den Territorien wesentlich von ihrer Akzeptanz in der Bevölkerung ab. Die Fürsten mußten deshalb auf regionale Kräfte mitunter erhebliche Rücksicht nehmen, und das selbst in jenen Provinzen, in denen sie sich kommissarisch durch einen Statthalter vertreten ließen. Im übrigen reichten die landesherrlichen Bestrebungen gar nicht so weit, das vorhandene Rechtsgefüge vollständig außer Kraft zu setzen ${ }^{9}$. Dauerhafte Institutionen, klare normative Bestimmungen sowie ein fester, den Fürsten verpflichteter Personalbestand dienten zwar dazu, altständische Verfassungselemente auszuhöhlen und die Krone gegenüber den intermediären Kräften zu stärken ${ }^{10}$. Die Existenz der ständisch-korporativen Rechtsordnung wurde durch sie jedoch nicht in Frage gestellt. In den Gebieten der geistlichen Wahlfürstentümer blieben die ständischen Strukturen sogar bis zur Säkularisation in ihren Grundfesten oftmals unerschüttert, zumal die Domkapitel, denen die Wahl der geistlichen Landesfürsten oblag, ihr Wahlrecht benutzten, um dem Für-

7 Dieter Grimm, Deutsche Verfassungsgeschichte 1776-1866, Frankfurt a.M. 1988, S. 13

8 Zum frühneuzeitlichen Verfassungsbegriff vgl. ibid. S.12f.; Heinz MoHNHAUPT, Verfassung (I.), in: Otto BrunNer u.a. (Hg.), Geschichtliche Grundbegriffe. Historisches Lexikon zur politisch-sozialen Sprache in Deutschland, Bd.6, Stuttgart 1990, S.832-862, hier S. 856f.; Dietmar WillowerT, Deutsche Verfassungsgeschichte: Vom Frankenreich zur Teilung Deutschlands, München 1990, S.1f.

9 BIRTSCH, Verfassung, S.54, bemerkt dazu treffend: "Es gehört zu den nur scheinbaren Paradoxien der Geschichte, daß der absolutistische Obrigkeitsstaat, der die ständische Autonomie bekämpfte, sich dieses Argument nicht zu eigen machte und die landständische Verfassung nicht völlig beseitigte. Die tiefere Ursache dafür wird man wiederum nicht schlicht in der beharrenden Kraft altüberlieferter Rechtsideen finden wollen, sondern vielmehr in der Tatsache, daß dieser Staat, weil er der Autorität bedurfte, sich der noch wirksamen ständischen Autoritäten bediente und sie seinen Interessen nutzbar zu machen suchte. "Siehe auch Gerhard DiLcher, Vom ständischen Herrschaftsvertrag zum Verfassungsgesetz, in: Der Staat 27 (1988) S.161-193, hier S. 177f.

10 Aus der umfangreichen Absolutismus-Forschung vgl. stellvertretend Ronald G. Asch, Heinz DuchHardT (Hg.), Der Absolutismus - ein Mythos? Strukturwandel monarchischer Herrschaft in West- und Mitteleuropa (ca. 1550-1700), Köln 1996; Reinhard BLÄNKNER, »Absolutismus« und »frühmoderner Staat«. Probleme und Perspektiven der Forschung, in: Rudolf Vierhaus u. a. (Hg.), Frühe Neuzeit - frühe Moderne? Forschungen zur Vielschichtigkeit von Übergangsprozessen, Göttingen 1992, S. 48-74; Johannes KUNISCH, Absolutismus. Europäische Geschichte vom Westfälischen Frieden bis zur Krise des Ancien Régime, Göttingen 1986, besonders S. 54f.; Walther HubatsCH (Hg.), Absolutismus, Darmstadt 1973; Fehrenbach, Ancien Régime. 
sten vor ihrer Huldigung Wahlkapitulationen zur Einschränkung seiner fürstlichen Macht abzuringen ${ }^{11}$.

In der historischen Forschung wurden Ständetum und Absolutismus lange Zeit aus der Perspektive des sich herausbildenden modernen Staates betrachtet. In diesem entwicklungsgeschichtlichen Ansatz wurde das Verhältnis zwischen Ständen und Landesherren auf ein dualistisches reduziert. Während die Stände vornehmlich als Gegenspieler des werdenden Staates und als Bewahrer tradierter Rechte betrachtet wurden, galten die Monarchen als Motoren und Träger des sich ausweitenden Staates. Je nach Standort des Historikers wurde entweder die Durchsetzung des autokratischen Herrschaftsanspruchs der Landesfürsten oder die herausragende Stellung der Stände betont. Dabei beschränkte sich das Forschungsinteresse vornehmlich auf die großen Vorläufer moderner Staatlichkeit. Kleinere und auf den ersten Blick weniger auf die Moderne verweisende Herrschaftsräume blieben völlig ausgeblendet. Neuere Arbeiten, an die hier angeknüpft wird, haben inzwischen einen Ausweg aus den Diskussionen über die Thematik gewiesen. Besonders die Landesgeschichte hat anhand regionaler Beispiele Grenzen, aber auch Spielräume ständischer Politik innerhalb der absolutistischen Politik aufgezeigt und damit zugleich deutlich gemacht, daß die Verfassungswirklichkeit äußerst komplex war und kaum mit dichotomen Deutungsschemata zu erklären ist. Die Vorteile dieser Untersuchungen sind vor allem in der Methode zu suchen: Erkenntnisleitend ist nicht mehr allein die zentralstaatliche Perspektive, sondern zugleich die Frage nach anderen Einflußfaktoren und Wirkmechanismen politischer Herrschaft. Großes Verdienst kommt in diesem Zusammenhang Peter Blickle zu. Er richtete erstmals den Blick auf genossenschaftliche Formen altständischer Partizipation und gab dadurch wichtige Anstöße bei der Frage der politischen Mitwirkungsmöglichkeiten im altständischen Ordnungsgefüge ${ }^{12}$.

11 Eine Ausnahme stellte das Reichsstift Essen dar, weil hier die ständische Ordnung zu Beginn des 18. Jahrhunderts abgeschafft und erst im Jahre 1792 wieder eingeführt wurde. Vgl. HömBerg, Landesgeschichte, S.262f.; Rothert, Absolutismus, S.136; BRAND, Geschichte, S.26f.; LaHRKamP, Münster, S.130f.; Rudolfine Freiin von OER, Landständische Verfassungen in den geistlichen Fürstentümern Nordwestdeutschlands, in: Peter BAUMGART (Hg.), Ständetum und Staatsbildung in Brandenburg-Preußen. Ergebnisse einer internationalen Fachtagung, Berlin, New York 1983, S.94-119.

12 Vgl. Peter Blickle, Landschaften im alten Reich. Die staatlichen Funktionen des gemeinen Mannes in Oberdeutschland, München 1973. Aus der umfangreichen Literatur über das Ständetum siehe stellvertretend Dietrich GERHARD, Regionalismus und ständisches Wesen als ein Grundthema europäischer Geschichte, in: HZ 174 (1952) S. 307-337; Francis Ludwig Carsten, Princes and Parliaments in Germany. From the Fifteenth to the Eighteenth Century, Oxford 1959; Eberhard WEIs, Kontinuität und Diskontinuität zwischen den Ständen des 18. Jahrhunderts und den frühkonstitutionellen Parlamenten von 1818/1819 in Bayern und Württemberg, in: Walter Demel, Bernd Roeck (Hg.), Deutschland und Frankreich um 1800. Aufklärung - Revolution - Reform, München 1990, S. 218-242; Burg, Verwaltung, S. 124f.; vgl. ferner folgende Sammelbände: Karl BosL (Hg.), Der moderne Parlamentarismus und seine Grundlagen in der ständischen Repräsentation, Berlin 1977; Gerhard, Ständische Vertretungen; BaumgarT, Ständetum und 
Wesentliche Konsequenz des Fortbestands der ständisch-korporativen Ordnung war, daß die politische Teilhabe trotz wiederholter Forderungen der Untertanen nach Anpassung der Repräsentationsverhältnisse an das gewandelte Profil von Staat und Gesellschaft bis zum Beginn der französischen Herrschaft unverändert auf altständischen Prinzipien beruhte. Demnach besaß nur ein begrenzter Kreis von Einwohnern die Möglichkeit, an der Herrschaft zu partizipieren. Weite Teile der Untertanen waren hingegen von der politischen Einflußnahme gänzlich ausgeschlossen. Durchlässigkeit zwischen beiden Gruppen gab es kaum.

Wie unbeweglich die Kriterien waren, die zur politischen Mitsprache führten, spiegelten die im Großherzogtum Berg noch vorhandenen landständischen Kollegien, das ritterschaftliche und das städtische ${ }^{13}$. Befähigt zur Mitgliedschaft in den landständischen Kurien der Ritterschaft waren grundsätzlich alle Eigentümer qualifizierter Rittergüter. In vielen Landesteilen mußten diese zusätzlich eine mehrfache Ahnenprobe erbringen ${ }^{14}$. Die Bindung der Landstandschaft an die Ahnenprobe erfolgte mit dem Ziel, die Aufnahme nobilitierter Rittergutsbesitzer in das Kollegium zu verhindern. Faktisch bewirkte sie starke Konzentrationsprozesse innerhalb der Adelskollegien, weil immer weniger Gutsbesitzer dazu imstande waren, die Ahnenprobe zu erfüllen. Der Kreis der landtagsfähigen Rittergutsbesitzer reduzierte sich daher zusehends, wodurch der ständische Adel erheblichen Legitimationszwängen ausgesetzt und langfristig geschwächt wurde. Dies war um so mehr der Fall, als die Inbesitznahme des linken Rheinufers durch Frankreich und die damit verbundene Ausscheidung des dort ansässigen Adels zu weiteren Einschnitten in die Personalstruktur der Ritterkurien führten. Beim Übergang der Herrschaft an

Staatsbildung. Kritisch zu Blickle: Volker Press, Herrschaft, Landschaft und »Gemeiner Mann « in Oberdeutschland vom 15. bis zum frühen 19. Jahrhundert, in: Zeitschrift für die Geschichte des Oberrheins 123 (1975) S. 169-214; ferner BLÄNKNER, "Absolutismus«, S. 64f.

13 In den altpreußischen Grafschaften Tecklenburg und Lingen sowie in der Grafschaft Limburg gab es nur noch das Kollegium der Ritterschaft. In der Reichsherrschaft Homburg setzte sich der Landesvorstand allein aus Bauern zusammen. Abgestimmt wurde in diesen Territorien daher nicht nach Kurien, sondern nach Köpfen. In der Grafschaft Bentheim waren die Stände auch nicht nach Kurien getrennt, sondern stimmten gleichberechtigt ab. Vgl. Hunsche, Landkreis, S.21f.; Kunna, Verfassung, S. 40; Karl HeckmanN, Geschichte der ehemaligen Reichsherrschaft Homburg an der Mark, Bonn 1939, S.83; KLueting, Ständewesen, S. 149f.; Richard CAPPElle, Beiträge zur Geschichte der Erbentage, namentlich derjenigen der Grafschaft Mark, Göttingen 1913, S.88; Ernst FiNKEMEYER, Verfassung, Verwaltung und Rechtspflege der Grafschaft Bentheim zur Zeit der hannoverschen Pfandschaft 1753-1804, in: Osnabrücker Mitteilungen 75 (1968) S.1-125, hier S. 26, 35 .

14 In den ehemals preußischen Gebieten mußten sie acht, im vormaligen Herzogtum Berg sechzehn adelige Generationen nachweisen. Vgl. das undatierte Tableau de l'administration civile et judiciaire des duchés de Clèves et de Berg sous le régime prussien (März 1806), angefertigt von Agar, AN, AF IV 1225; siehe ferner ENGELBRECHT, Herzogtum, S.88f.; KuHNA, Verfassung, S.41f. 
Joachim Murat im Jahre 1806 erfüllten in Kleve von 47 Rittergutsbesitzern nur noch drei, in Berg von 160 allein 38 die obligatorische Ahnenprobe ${ }^{15}$.

Verkrustungserscheinungen kennzeichneten auch die ständischen Landeskollegien der Städte, die im rechtsrheinischen Teil des Herzogtums Kleve die Städte Wesel, Emmerich, Duisburg und Rees, in der Grafschaft Mark Hamm, Unna, Kamen, Iserlohn, Schwerte und Lünen, in den säkularisierten Reichsabteien die gleichnamigen Städte Essen und Werden und im Herzogtum Berg Düsseldorf, Ratingen, Lennep und Wipperfürth umfaßten. Die Mehrzahl von ihnen befand sich in finanziell und ökonomisch zerrütteten Verhältnissen, so daß kaum mehr erkennbar war, auf welchen Kriterien ihre Landtagsfähigkeit beruhte. Nur noch wenige der in den Landeskollegien vertretenen Städte besaBen innerhalb ihrer Provinzen eine herausragende Stellung. Der überwiegende Teil von ihnen wurde demgegenüber von anderen, in den Kollegien nicht repräsentierten Orten übertroffen. Die Zusammensetzung der städtischen Landeskollegien entsprach mithin kaum noch den realen Gegebenheiten ${ }^{16}$.

Zur Vergrößerung der Diskrepanz zwischen Verfassungsnorm und -wirklichkeit trug überdies bei, daß bei der Aufnahme in die ständischen Städtekorpora innerstädtische Wandlungsprozesse keine Berücksichtigung fanden ${ }^{17}$. Zutritt zum Landtag besaßen allein die führenden Amtsträger der Städte und eo ipse die Mitglieder der alteingesessenen städtischen Führungsgruppen. Aufsteigenden, aber im Stadtregiment bisher nicht vertretenen Kräften war die Mitgliedschaft weithin versperrt. Zwar akzeptierten die von der Teilnahme ausgeschlossenen Bevölkerungskreise immer weniger die oligarchischen Strukturen in den Städten, was zu zahlreichen Reibereien und Konflikten führte ${ }^{18}$. Aber sie vermochten nicht an den Grundfesten der bestehenden Verhältnisse zu rütteln. Die Zugangsvoraussetzungen zu den Landeskollegien bestanden unverändert fort. Wenn es zu Modifikationen in der Personalstruktur der städtischen Magistrate kam, wie es etwa in den altpreußischen Provinzen

15 Undatiertes Tableau de l'administration civile et judiciaire des duchés de Clèves et de Berg sous le régime prussien (März 1806), angefertigt von Agar, AN, AF IV 1225; vgl. Kunna, Verfassung, S.43f. Auch in Territorien, in denen es keine Ahnenprobe gab, kam es zu Konzentrationsprozessen. In Limburg etwa waren nur noch zwei Familien im Besitz der fünf Landtagsstimmen. KLUETING, Ständewesen, S.153f.

16 Vgl. Kuhna, Verfassung, S.46f.; Engelbrecht, Herzogtum, S. 18.

17 Die Städte entsandten aus dem ehemaligen oder aktuellen Kreis ihrer Bediensteten jeweils zwei Deputierte zu den Landtagen. Undatiertes Tableau de l'administration civile et judiciaire des duchés de Clèves et de Berg sous le régime prussien (März 1806), angefertigt von Agar, AN, AF IV 1225; siehe KuHNA, Verfassung, S.46; Engelbrecht, Herzogtum, S.206; zur Zusammensetzung der bergischen Ritterschaft vgl. Theodor Johann Joseph Lenzen (Hg.), Beyträge zur Statistik des Herzogthums Berg, Bd.2, Düsseldorf 1805, S.86f.; ENGELBRECHT, Herzogtum, S.88f.

${ }_{18} \mathrm{Zu}$ Auseinandersetzungen kam es namentlich in den altpreußischen und bergischen Gebieten. Dazu KuHNa, Verfassung, S.46; Klaus Müller, Bürgerproteste und Handwerkerunruhen im Herzogtum Berg in der Zeit der Französischen Revolution, in: Helmut Berding (Hg.), Soziale Unruhen in Deutschland während der Französischen Revolution, Göttingen 1988, S.92-110; EnGELBRECHT, Herzogtum, S. 72f., 248f. 
der Fall war ${ }^{19}$, geschah dies allenfalls auf Kosten städtischer Mitsprache. An die Stelle gewählter Deputierter traten königliche Bedienstete.

Der Zugang zu den regionalen Zusammenschlüssen der Erben- und Kirchspieltage war nicht ganz so starr geregelt wie der zu den ständischen Kollegien. Entscheidend für die Aufnahme in diese Versammlungen waren in erster Linie die Besitzverhältnisse. Die breiteste soziale Basis besaßen hierbei die Steuererbentage der altpreußischen Provinzen Kleve und Mark. Sie schlossen neben adeligen Gutsbesitzern und Domänenrentmeistern auch grundbesitzende Bauern und Bauerschaftsvorsteher als Vertreter der besitzlosen Bauern $e^{20}{ }^{20}$. Die Repräsentation der Bauern auf den Erbentagen variierte entsprechend der Agrarstruktur der einzelnen Territorien beträchtlich ${ }^{21}$. Im Norden der Grafschaft Mark wurden die Erbentage vom Adel dominiert. Im Süden der Grafschaft vermochten die Bauern den Adel teilweise ganz zu verdrängen $^{22}$. Ständischen Prinzipien stärker verpflichtet waren die Kirchspielkonventionen in den Gebieten des ehemaligen Fürstentums Münster. Aufnahme in diese Körperschaften fanden allein Fürstendiener und Gutsbesitzer. Die Bauern konnten zwar an den Konventionen teilnehmen, verfügten aber trotz wiederholt vorgebrachter Bitten über kein Stimmrecht ${ }^{23}$.

19 Dieter Stievermann, Preußen und die Städte der westfälischen Grafschaft Mark im 18. Jahrhundert, in: Westfälische Forschungen 31 (1981) S.5-33, hier S. 9f.; Rüdiger ReINHARDT, Die Besonderheiten der preußischen städtischen Verwaltung in den Grafschaften Mark und Ravensberg im 18. Jahrhundert, Diss. jur. Münster 1968, S.71f.

20 Jüngere Literatur zu den Erbentagen in Kleve und Mark: Harm Klueting, Bauern auf den »Erbentagen $\ll$ nordwestdeutscher Territorien, in: Parliaments, Estates \& Representation 7 (1987) S.41-49; Stefan GorIssEN, Die Steuerreform in der Grafschaft Mark 1791. Ein Modell für die Stein-Hardenbergschen Reformen?, in: Stefan BraKensieK u. a. (Hg.), Kultur und Staat in der Provinz. Perspektiven und Erträge der Regionalgeschichte, Bielefeld 1992, S.189-212, hier S.201f., 209f.; Burg, Verwaltung, S. 133; Wilfried ReIninghaus, Die Wirkung der Steuern auf Wirtschaft und Gesellschaft in der Grafschaft Mark im 18. Jahrhundert, in: Eckart Schremmer (Hg.), Steuern, Abgaben und Dienste vom Mittelalter bis zur Gegenwart, Stuttgart 1994, S. 149-169, hier S.168. Aus der älteren Literatur: CAPPElle, Beiträge; Karl LichthardT, Studien zur Entwicklung der Erbentage und der Amtsverfassung in Cleve-Mark, in: Jahrbuch des Vereins für Orts- und Heimatskunde in der Grafschaft Mark 24 (1909/1910) S.1-128.

21 Zur sozialgeschichtlichen Problematik des Bauernbegriffs vgl. Christof DiPPER, Bauern als Gegenstand der Sozialgeschichte, in: Wolfgang ScHIEDER, Volker SELlin (Hg.), Sozialgeschichte in Deutschland. Entwicklungen und Perspektiven im internationalen Zusammenhang, Bd. 4: Soziale Gruppen in der Geschichte, Göttingen 1987, S.9-33, hier S. 23f.

22 Klueting, Bauern, S. 44f. Die Forderungen des märkischen Adels, die Bauern aus dem Kreis der Abgeordneten auszuschließen, blieben wirkungslos. Die preußische Regierung gedachte die regionalen Rekrutierungskriterien schon allein aus pragmatischen Gründen nicht anzutasten, mehr noch: Sie versuchte das aristokratische Element zugunsten nichtadeliger Grundbesitzer zurückzudrängen.

23 KuHNa, Verfassung, S.134f.; LichtHARDT, Studien, S. 122; Burg, Verwaltung, S.138. Neben den angeführten Beispielen Kleve-Mark und Münster fanden Erbentage mit ähnlichen Funktionen auch in der Herrschaft Gimborn-Neustadt und in der Abtei Werden statt. In der Grafschaft Limburg waren sie im 18. Jahrhundert mit dem Landtag verschmolzen worden. Vgl. KLueting, Ständewesen, S. 145f., 148f.; CAPPElle, Beiträge, S. 71f., 87f. Auch 
Während der Kreis der Mitspracheberechtigten kaum modifiziert worden war, hatten die ständischen Korporationen funktional mehr und mehr an Bedeutung verloren. Personell kam die Erosion der ständischen Herrschaftsfunktionen in der Zurückdrängung ständischer Adeliger zugunsten bürgerlicher Räte innerhalb der Regierungs- und Verwaltungsbehörden zum Ausdruck. Rechtlich manifestierte sie sich in der zunehmenden Aufhebung ständischer Privilegien, besonders im jurisdiktionellen Bereich. Darüber hinaus spiegelte sich der sinkende Einfluß der Landeskollegien in einem der vornehmsten Bereiche ständischer Mitsprache: dem der Finanzen. Obgleich die Landtage nach wie vor die jährlich zu erhebende Steuersumme bewilligten, lag die Festlegung des Steuerquantums zunehmend in der Hand des Monarchen und konnte von den Landeskollegien immer seltener blockiert, geschweige denn korrigiert werden.

Der funktionale Verfallsprozeß der Landstände machte sich im 18. Jahrhundert allenthalben bemerkbar, verlief aber in den einzelnen Territorien nicht synchron bzw. linear und nahm auch nirgendwo identische Züge an $^{24}$. In einzelnen Territorien, namentlich den altpreußischen Provinzen Kleve und Mark, kam den altständischen Vertretungen beim Übergang der Herrschaft an den Prinzen Murat noch eine gewisse Daseinsberechtigung zu. In Gebieten wie dem ehemaligen Herzogtum Berg hatten die Landstände demgegenüber bereits erheblich an Bedeutung eingebüßt oder waren, wie in den nassau-oranischen Besitzungen und säkularisierten Gebieten des vormaligen Fürstbistums Münster und Kurkölns, gar nicht oder nicht mehr existent. Die Unterschiede, die zwischen den einzelnen Territorien in der Ausprägung der korporativen Verfassung bestanden, wurzelten dabei in regionalen Sonderentwicklungen.

Beispielsweise hing die Lebendigkeit der Ständeverfassung im Herzogtum Kleve und der Grafschaft Mark zu Beginn des 19.Jahrhunderts eng mit dem Siebenjährigen Krieg zusammen. Die verheerenden Folgen der kriegerischen Auseinandersetzungen in beiden Provinzen hatten den preußischen König

im Herzogtum Berg fanden Amtsversammlungen statt, so unter anderem in Elberfeld. Indessen besaßen sie keinen so hohen Institutionalisierungsgrad wie etwa die kleve-märkischen Erbentage. Aus diesem Grund ist sich die Geschichtsforschung bis heute nicht über ihre Bewertung einig. Klueting, Bauern, S. 42, 47, und CAPPELle, Beiträge, S. 90, sehen in den bergischen Amtsversammlungen keine den märkischen Erbentagen vergleichbaren Einrichtungen. Nach Klueting wurden die Aufgaben der Erbentage im Herzogtum Berg durch landesherrliche und ständische Deputierte erledigt. Cappelle sieht in den Amtseingesessenen nicht mehr als ein Werkzeug bei der Verteilung und Erhebung der Steuern. Funktionale und personelle Verbindungslinien zwischen Erbentagen und bergischen Amtsversammlungen konstatieren demgegenüber Rainer WALz, Stände und frühmoderner Staat. Die Landstände von Jülich-Berg im 16. und 17. Jahrhundert, Neustadt a.d. Aisch 1982, S. 188f.; WrTtuÜtz, Duché, S. 173.

24 Zur unterschiedlichen Ausprägung des Ständewesens in den deutschen Territorien am Ausgang des 18. Jahrhunderts vgl. Press, Landstände; Rudolf VIERHAus, Ständewesen und Staatsverwaltung in Deutschland im späteren 18. Jahrhundert, in: DERS., Manfred BotzeNharT (Hg.), Dauer und Wandel der Geschichte. Aspekte europäischer Vergangenheit. Festschrift für Kurt von Raumer, Münster 1966, S.337-360, hier S.337f. 
dazu veranlaßt, die Stände, die im Zuge des Ausbaus der absolutistischen Macht beinahe vollständig aus dem politischen Leben verdrängt worden waren, wieder mehr an der Politik zu beteiligen ${ }^{25}$. Seither wurden die Stände stärker in die Provinzialverwaltung eingebunden und erhielten Aufgaben im Rahmen der Steuerrepartition, der Militäraushebung sowie des Landesschuldenwesens $^{26}$. Außerdem trat der Landtag wieder regelmäßig zusammen ${ }^{27}$. Darüber hinaus erledigten die regionalen Zusammenkünfte, die Erben- und Kirchspieltage, weiterhin verschiedene Aufgaben namentlich in der Steuerverwaltung ${ }^{28}$. Die ständefreundliche Politik Preußens in den rheinisch-westfälischen Provinzen hatte allerdings ihre Grenzen ${ }^{29}$ : Angelegenheiten, die das Staatsinteresse berührten, wurden in Berlin geregelt ${ }^{30}$. Daneben hielt die preußische Krone die ständischen Herrschaftsaufgaben, die der zwischen dem

${ }^{25}$ Dazu zwang ihn allein schon die mit dem Wiederaufbau der Gebiete notwendig gewordene Schuldentilgung. Jürgen Kloosterhuis, Fürsten, Räte, Untertanen. Die Grafschaft Mark, ihre lokalen Verwaltungsorgane und die Regierung zu Kleve, in: Der Märker 35 (1986) S. 147-164, hier S. 152; Hartlieb von Waldthor, Eingliederung, S. 236; KuhNa, Verfassung, S. 39; SMETs, Les pays rhénans, S.39f. Dagegen schreibt Otto Hintze, die ständischen Organe seien aufgrund fehlender Tätigkeiten allmählich unbedeutend geworden: DERS., Der preuBische Militär- und Beamtenstaat im 18. Jahrhundert, in: HUBaTsCH, Absolutismus, S.45-56, hier S.46.

${ }^{26}$ Leo Wollenhaupt, Die Cleve-Märkischen Landstände im 18. Jahrhundert, Berlin 1924 (ND Lübeck 1965), S.88f.; KuhNa, Verfassung, S.63f.; StievermanN, Absolutistischer Zentralismus, S.62f.

27 WollenhauPT, Landstände, S. 67.

28 Lichthard, Studien, S.42f.; Cappelle, Beiträge, S. 59f.; Klueting, Bauern, S.42f. Die von den Erbentagen in den altpreußischen Provinzen um 1800 ausgeübten Funktionen werden in der historischen Forschung sehr unterschiedlich beurteilt. KLuEting, Bauern, S. 43f., 46f., betrachtet die Erbentage auf der Folie ihrer Genese in der absolutistischen Herrschaftspolitik des brandenburgischen Kurfürsten und sieht in ihnen daher primär fürstliche Herrschaftsinstrumente zur Aufhebung der ständischen Beteiligung an der Steuererhebung und zur Beschränkung kommunaler Herrschaftsrechte, aber keine Selbstverwaltungsorgane. Dagegen konzentriert sich LichTHARDT, Studien, besonders S. 42f., 127f., in erster Linie auf den Wirkungskreis der Erbentage und kommt dabei zu dem Schluß, daß sich die Erbentage sowohl als landesherrliche als auch als kommunale Organe entfalten konnten. Des weiteren bildeten sie für ihn ein wichtiges Bindeglied zwischen landesherrlichen und kommunalen Interessen. Auch Gorissen, Steuerreform, S.199f., 209f.; KuHNa, Verfassung, S.76f., und Reininghaus, Wirkung, S. 150, 168, finden insgesamt zu einem eher positiven Urteil über die Bedeutung der Erbentage als kommunale Verwaltungsorgane.

29 Siehe den Aufsatz von Günther BIRTsch, Preußischer Hochabsolutismus und Stände, in: BaUmGarT, Ständetum und Staatsbildung, S.389-408. Im Gegensatz zu Kleve und Mark verloren die Tecklenburger und Lingener Landeskollegien die Periodizität ihrer Landtage und besaßen nur noch das Präsentationsrecht für das Landratsamt. Allerdings bestand selbst dieses nur noch in eingeschränktem Maße und wurde häufig vom preußischen Landesherrn übergangen. Dazu Hunsche, Landkreis, S. 26, 32f.

${ }^{30}$ Das zeigte sich beispielsweise bei der Ausarbeitung des Allgemeinen Landrechts. Vgl. Günther BirTsCH, Gesetzgebung und Repräsentation im späten Absolutismus. Die Mitwirkung der preußischen Provinzialstände bei der Entstehung des Allgemeinen Landrechts, in: HZ 208 (1969) S. 265-294. 
Haus Brandenburg und den klevisch-märkischen Ständen im 17.Jahrhundert geschlossene Herrschaftskompromiß ausdrücklich verbriefte, weiterhin begrenzt $^{31}$.

Auf ständischer Seite wußte man durchaus von der Chance zur Mitarbeit zu profitieren. Gerade die ritterbürtigen Adeligen waren zur erneuten Kooperation mit der Berliner Regierung bereit, und es gelang ihnen in den Folgejahren, verlorengegangene Verwaltungspositionen zurückzuerobern. Wie die gelehrten Räte waren sie fortan jedoch dazu gezwungen, sich von geburtsständischen Kriterien zu lösen und rationalen Leistungsmustern zu beugen ${ }^{32}$. Darüber hinaus nutzten die Stände die Möglichkeiten zur Teilnahme am politischen Tagesgeschäft mitunter, um eigene Interessen durchzusetzen. Die landtagsfähigen Städte beispielsweise erreichten im Jahre 1791, daß den Mitgliedern der Ritterschaft Teile ihrer Steuerprivilegien entzogen wurden ${ }^{33}$. Die märkischen Stände setzten im Jahre 1804 durch, daß der Landtag von Wesel nach Hamm verlegt und damit dem Statusverlust, den die klevischen Stände durch die französische Besetzung des linken Rheinufers erlitten hatten, wie auch ihrem Wunsch, sich von den klevischen Ständen zu emanzipieren, Rechnung getragen wurde ${ }^{34}$. Weniger Durchsetzungsvermögen gegenüber Berlin besaßen die Landeskollegien Essens und Werdens. Zwar blockierten sie erfolgreich die Bestrebungen der preußischen Regierung, die Teilnahme der Stände am politischen Entscheidungsprozeß zu unterbinden, ohne diese völlig aus dem Verfassungsgefüge zu eliminieren. Berlin nahm daraufhin 1803 von seiner Ausgrenzungspolitik Abstand und bestätigte die Landstände. Allerdings vermochten die Essener und Werdener Landstände nicht zu verhindern, $\mathrm{daß}$ sie mit den kleve-märkischen Landständen vereinigt wurden ${ }^{35}$. Während

31 Im Herrschaftskompromiß von 1660/1661 wurden den Ständen das Indigenat und das Steuerbewilligungsrecht zugesichert, während der Fürst die Gewalt über das Heer und die Behördenorganisation erhielt. Dazu KLoosterHuIs, Fürsten, S. 151f., 156; SmETs, Les pays rhénans, S.39f.

32 Zugute kam ihnen, daß das Allgemeine Landrecht von 1794 das Ämterprivileg des Adels ausdrücklich bestätigte: Allgemeines Landrecht für die Preußischen Staaten von 1794. Mit einer Einführung von Hans Hattenhauer und einer Bibliographie von Günther Bernert, Frankfurt a.M., Berlin 1970, II, 9, Art.34; vgl. ferner Vierhaus, Ständewesen, S.356f.; Henning von BoNIN, Adel und Bürgertum in der höheren Beamtenschaft der preußischen Monarchie 1794-1806, in: Jahrbuch für die Geschichte Mittel- und Ostdeutschlands 15 (1966) S.139-174; BuRG, Verwaltung, S. 161f.; Reinhart KoselLeck, PreuBen zwischen Reform und Revolution. Allgemeines Landrecht, Verwaltung und soziale Bewegung von 1791 bis 1848, Stuttgart ${ }^{2} 1975$, S. 78f.; Elisabeth FehrenBach, Der Adel in Frankreich und Deutschland im Zeitalter der Französischen Revolution, in: Helmut Berding u. a. (Hg.), Deutschland und Frankreich im Zeitalter der Französischen Revolution, Frankfurt a. M. 1989, S.177-215, hier S. 199f.; WollenHAuPT, Landstände, S. 97f.; KLooSTERHUIS, Fürsten, S.152, 157.

33 Reininghaus, Wirkung, S.168f.; Kuhna, Verfassung, S. 51f.

34 Ibid. S. 48f.; KLoOSTERHUis, Fürsten, S. 152.

35 Sie waren gegen diese Auflage, weil die Eingliederung aufgrund der in den altpreußischen Provinzen herrschenden strengen Aufnahmekriterien in das Adelskolleg unweiger- 
beide Gebiete jeweils einen Vertreter in das Städtekollegium entsandten, wurde nur ein Mitglied des Essener Adels in die Ritterkurie aufgenommen. Die bis dahin in Essen und Werden vertretenen Bauernschaften verloren ihre Mitspracherechte vollständig 36 .

Die Landstände des bayerischen Herzogtums Berg erlebten eine etwas andere Entwicklung als die von Kleve und Mark. Während die kleve-märkischen Kollegien von der preußischen Krone in der ersten Hälfte des 18. Jahrhunderts zunächst entmachtet und nach dem Siebenjährigen Krieg wieder aufgewertet worden waren, hatten die wittelsbachischen Landesfürsten den Ständen ihres niederrheinischen Außenpostens bis zum letzten Drittel des 18. Jahrhunderts durchgehend Handlungsspielräume zugebilligt ${ }^{37}$. Nicht immer geschah dies ohne vorhergehende Auseinandersetzungen mit den auf die Bewahrung ihrer althergebrachten Rechte bedachten Landständen ${ }^{38}$. Letztlich blieben jedoch die Verbindlichkeiten der zwischen Landesfürst und Ständen im 17. Jahrhundert ausgehandelten Herrschaftsverträge gewahrt. Die bergischen Landstände vermochten auf diese Weise ihren Einfluß auf die Landespolitik weitaus stärker und länger zu konservieren als die Landstände in Kleve und in der Mark ${ }^{39}$. Mit dem Regierungsantritt Maximilians IV. Joseph im Jahre 1799 änderte sich diese Situation. Seitdem sahen sich die bergischen Stände mit ähnlichen Funktionsverlusten konfrontiert wie die altpreußischen Landeskollegien in der ersten Hälfte des 18. Jahrhunderts. Das landständische Gefüge verlor mehr und mehr an Wirkung und Bedeutung ${ }^{40}$.

Daß der bayerische Landesfürst nicht mehr gewillt war, die Stände am politischen Geschehen zu beteiligen, signalisierte er schon dadurch, daß er den

lich eine weitere Schwächung der stiftischen Ständestruktur bedeutete, zumal diese schon im Rahmen der Säkularisation partiell außer Kraft gesetzt worden war. Durch die Auflösung des Kapitels waren nämlich die beiden ersten Stände bereits aufgehoben. Vgl. BRAND, Geschichte, S. 11.

${ }^{36}$ Damit verschoben sich in Essen die Gewichte zugunsten der städtischen Kommunen. Unter der Fürstäbtissin hatte sich die Ritterbank aus sieben Rittersitzen und dem Stift Stoppenberg zusammengesetzt, während einzelne Städte und Herrschaften als »Nebenkontribuenten« auftgetreten waren. Vgl. Klueting, Ständewesen, S.150; Brand, Geschichte, S.16ff; HARTLieb von Wallthor, Eingliederung, S.241; KuhNa, Verfassung, S.154f.; ferner Robert DE VRIEs, Die Landtage des Stiftes Essen. Ein Beitrag zur Verfassungsgeschichte der geistlichen Territorien, in: Beiträge zur Geschichte von Stadt und Stift Essen 52 (1934) S.1-168, hier S. 30f., 39f.

37 Die Unterherrschaften versammelten sich zu Unterherrentagen, auf denen sie die jährlich an den bergischen Herzog für den ihnen gegenüber geleisteten Schutz zu entrichtende Summe festlegten. Dazu Carl Friedrich Wiebexing, Beiträge zur Churpfälzischen Staatengeschichte vom Jahre 1742 bis 1792, vorzüglich in Rücksicht der Herzogthümer Jülich und Berg, Heidelberg, Mannheim 1793, S. 2; Croon, Stände, S.4f.; Vollmer, Anspruch, S. 243. 38 Bei diesen Konflikten kamen den Landständen die Institutionen des Alten Reiches zur Hilfe, allen voran der Reichshofrat. ENGELbRECHT, Herzogtum, S.52, 87; vgl. allgemein Georg-Christoph von UNRUH, Die Wirksamkeit von Kaiser und Reich, in: JeSERICH u.a., Deutsche Verwaltungsgeschichte, S. 268-278, hier S.272, 275f.; PrEss, Landstände, S. 135f.

39 Engelbrecht, Herzogtum, S.49f.; WITtMÜtz, Duché, S.171f.

40 Press, Landstände, S. $135 f$. 
Thron bestieg, ohne zuvor die Huldigung der bergischen Landstände empfangen zu haben. In den Folgejahren machte Maximilian IV. noch mehr als beim Antritt der Herrschaft deutlich, daß er sich in der Landespolitik keinesfalls von den landständischen Vertretungen behindern zu lassen gedachte. Zahlreiche nach 1799 erlassene gesetzliche Neuerungen entstanden ohne ständische Mitarbeit. Qualifizierte und dem Fürsten gegenüber zur Loyalität verpflichtete Amtsdiener traten in der Verwaltung an die Stelle ständischer Adeliger. Widerstände aus den Reihen der Landstände gegen die stillschweigende Umgehung ständischer Privilegien blieben ungehört ${ }^{41}$.

Wesentliche Bedingungsfaktoren für die antiständische Politik, die der neue Landesherr am Niederrhein verfolgte, waren die territorialen und politischen Umwälzungen, die das Vordringen der französischen Revolutionsarmeen in Europa ausgelöst hatte. Hinzu trat, daß die bergischen Landstände, anders als beispielsweise jene in Kleve-Mark, zu schwach und auch nicht entwicklungsfähig genug waren, um sich der zunehmenden Entmachtung durch den Landesfürsten wirksam entgegenzustellen. Sie unternahmen nur geringe Kraftanstrengungen, um die Münchner Regierung zu einer ständefreundlicheren Haltung zu bewegen. Eine wirkungsvolle Obstruktion der Regierungspolitik scheiterte vor allem an der fehlenden Kohäsion der Stände. Während die Korporationen Kleve-Marks zumindest in der Lage waren, bei der Abwehr landesherrlicher Interventionen gemeinsam vorzugehen, fanden sich Ritterschaft und Städte in Berg nicht zu einer gemeinsamen Front im Kampf gegen das Ausgreifen der Landesherrschaft zusammen. Sie besaßen nicht einmal genügend Stärke und Zusammenhalt, um die Interessen ihres eigenen Kollegiums nachhaltig zu artikulieren. Insbesondere innerhalb der Ritterschaft als der potenteren der beiden Landstandschaften konnte von einer monolithischen Interessenvertretung nicht mehr die Rede sein. Politik wurde hier von einer kleinen Gruppe Adeliger gemacht. Die Landtage waren dagegen bloße Akklamationsorgane. Zur Schwächung des Ritterkollegiums trug außerdem bei, $\mathrm{daß}$ sich die in kurfürstlichen Diensten stehenden Adeligen innerhalb der Kurie von den übrigen Mitgliedern abspalteten und zu einer antiständischen Oppositionsbewegung formierten ${ }^{42}$.

Im Gegensatz zu Kleve, Mark und Berg existierten in den nassau-oranischen Territorien Dillenburg, Siegen und Hadamar ${ }^{43}$, in der mediatisierten und an Nassau-Oranien gefallenen Grafschaft Dortmund sowie in den säkularisierten Gebieten Münsters und Kurkölns bei ihrem Übergang an Murat keine Landstandschaften. Die Erbländer des Hauses Nassau-Oranien kannten Landstände überhaupt nicht. Demgegenüber verloren die säkularisierten und mediatisierten Gebiete ihre landständischen Organe durch die Gebietsver-

41 Engelbrecht, Herzogtum, S. 205f.; Müller, Das Haus, S. $18 f$.

42 Engelbrecht, Herzogtum, S.86f., 204f., 252f.; Müller, Das Haus, S. 18f.

43 Brief Joachim Murats an Napoleon vom 24. August 1806, abgedruckt in: Lettres et documents, Bd.4, Nr. 2493, S. 324f., hier S. 325. 
schiebungen nach $1800^{44}$. So wurden die von der Bürgerschaft gewählten Kollegien der Reichsstadt Dortmund, die sich aus dem Rat, dem Erbsassen- und dem Vierundzwanzigerstand zusammensetzten, nach der Mediatisierung und Integration Dortmunds in den nassau-oranischen Herrschaftsverband im Jahre 1803 aufgelöst und durch eine Regierung sowie einen um ein Vielfaches verkleinerten Magistrat ersetzt, dessen Zusammensetzung und Funktionen nunmehr preußischen Leitlinien folgten. Die Mitglieder beider Organe wurden künftig vom oranischen Erbprinzen ernannt. Dortmund fand auf diesem Wege, wenn auch mit erheblicher Verspätung, Anschluß an die preußischen Reformen des 18. Jahrhunderts ${ }^{45}$.

Ein den Kollegien der Reichsstadt Dortmund vergleichbares Schicksal teilten die Landstände des ehemaligen Fürstbistums Münster. Auch sie fielen den territorialen Umschichtungsprozessen nach 1800 zum Opfer - und das, obwohl gerade die adeligen Landstände, allen Vorwürfen, die im letzten Drittel des 18.Jahrhunderts gegenüber der Existenz geistlicher Fürstentümer geäußert worden waren ${ }^{46}$, und allen Widerständen aus den eigenen Reihen zum Trotz, ihre Position unangefochten $\mathrm{zu}$ bewahren vermocht hatten ${ }^{47}$. Nachdem die preußische Regierung schon bei der Besitzergreifung der stiftischen Länder zu erkennen gegeben hatte, daß sie nicht beabsichtigte, die ständische Teilnahme aufrechtzuerhalten, besiegelte Artikel 3 des Reichsdeputationshauptschlußes endgültig das Schicksal der Stände des ehemaligen Fürstbistums. Darin wurde die vollständige Auflösung der ständischen Verfassung in Münster stipuliert ${ }^{48}$. Die Reaktivierung der Landstände durch das französische Militärgouvernement im Jahre 1806 änderte an diesem Zustand nichts, zumal die Stände nicht in ihre einstigen politischen Funktionen zurückversetzt wurden. Beim Übergang der ehemals fürstbischöflichen Gebiete an das Großherzogtum Berg waren die Stände daher faktisch aufgehoben ${ }^{49}$. Nur die seit der Frühen Neuzeit bestehenden Kirchspielkonventionen bestanden weiterhin ${ }^{50}$.

\footnotetext{
44 Im kurkölnischen Vest Recklinghausen hob der Herzog von Arenberg am 26. Juli 1806 die ständische Vertretung auf. Vgl. Aloys DickmanN, Zur rechtlichen Stellung der Ritterbürtigen im Veste Recklinghausen mit besonderer Berücksichtigung der Bottroper Verhältnisse, in: Vestisches Jahrbuch 63 (1961) S.12-24, hier S. 14; Ludwig BETTE, Das Vest Recklinghausen in der arenbergischen und französischen Zeit (1802-1813), in: Vestische Zeitschrift 18 (1908) S.1-80, hier S. 28.

45 Schambach, Stadtbürgertum, S. 22f., 40f.; LahrKamp, Die französische Zeit, S.16.

46 Rothert, Absolutismus, S. 319f.; LAHRKamp, Münster, S. 9 f.

47 Vgl. Engelbrecht, Probleme, S. 417.

48 Hauptschluß der außerordentlichen Reichsdeputation vom 25. Februar 1803, Art.3, abgedruckt in: Ernst Rudolf HubER (Hg.), Dokumente zur deutschen Verfassungsgeschichte, Bd.1: Deutsche Verfassungsdokumente 1803-1850, Stuttgart u. a. ${ }^{31978, ~ S .1-28, ~ h i e r ~ S .3 . ~}$ Das Domkapitel lebte allerdings noch bis 1806 fort.

${ }^{49}$ Schreiben Agars an Joachim Murat vom 6. Juli 1808, ADD, Fonds Mosbourg, 100 MI 119; siehe auch Heinrich KocHENDöRFFER, Territorialentwicklung und Behördenverfassung von Westfalen 1802-1813, in: Zeitschrift für vaterländische Geschichte und Altertumskunde 86 (1929) S. 97-218, hier S.114; LaHRKamp, Münster, S. 135; Dies., Die französische Zeit, S.13f.

50 HaRTLIEB von Wallthor, Eingliederung, S.242.
} 


\section{Verwaltungsbehörden}

Mit den funktionalen Bedeutungsverlusten der altständischen Vertretungen im ausgehenden 18. und beginnenden 19. Jahrhundert korrelierten der Aufund Ausbau der fürstlichen Administration. Abgesehen davon, daß die landesherrliche Verwaltung mehr und mehr Aufgaben übernahm, die einst von den ständischen Korpora erledigt worden waren, zeichnete sich die Tendenz ab, den Behördenapparat von altständischen Organisationsmustern zu befreien und nach bürokratischen Prinzipien zu normieren ${ }^{51}$. Die landesherrlichen Reformbestrebungen bezweckten hierbei einerseits, die Machtverschiebungen zugunsten der Krone abzusichern. Andererseits dienten sie dazu, die Verwaltung für die wachsenden Herrschaftsaufgaben dauerhaft leistungsfähig zu machen ${ }^{52}$.

$\mathrm{Zu}$ Reorganisationsansätzen kam es zunächst auf institutioneller Ebene. Innerhalb des bestehenden Behördengefüges wurden altständische Organe zusammengeschmolzen oder durch neue Institutionen beiseite geschoben. Ad hoc gebildete und zunächst nicht fest eingerichtete Organe konsolidierten sich und wurden zu dauerhaften Einrichtungen. Ferner traten Sonderbehörden aus den bestehenden Institutionen heraus. Diese Abspaltung von Fachbehörden erfolgte entweder in Reaktion auf einen größeren Bedarf an Spezialisierung oder war auf Unzulänglichkeiten bestehender Einrichtungen zurückzuführen. Ebenso schoben sich neue Institutionen zwischen die bereits existierenden und verursachten Funktionsverschiebungen oder Bedeutungsverluste. Daneben wurden altständische Einrichtungen der landesherrlichen Aufsicht unterstellt und langfristig in den fürstlichen Behördenapparat integriert ${ }^{53}$.

Parallel zu den institutionellen Veränderungen erfolgten Maßnahmen zur Reformierung des Verwaltungspersonals. Da die Effizienz der neuen Verwaltungsorgane nur durch ein entsprechend ausgebildetes Personal gewährleistet war, wurde die Frage des Nachwuchses nicht mehr ausschließlich durch geburtsständische Kriterien geregelt. Über die Aufnahme in den Verwaltungs-

51 Bürokratie wird hier verstanden wie bei Lenore O'Boyle, Some Recent Studies of Nineteenth-Century European Bureaucracy: Problems of Analysis, in: Central European History 19 (1986) S.386-408, hier S.387f.: "Bureaucracy may be defined as a method, that is, administration of a government chiefly through bureaus staffed with nonelective officials following inflexible rules of operation, and as a body of men, that is, the officials staffing such bureaus. These officials are arranged in a hierarchy of appointed and removable, salaried, trained civil servants, equiped with definite commissions to perform specific functions.« Zur Geschichte und Semantik des Bürokratie-Begriffs ferner: Bernd WUNDER, Geschichte der Bürokratie in Deutschland, Frankfurt a.M. 1986, S.7f.; Herbert voN BoRCH, Obrigkeit und Widerstand. Zur politischen Soziologie des Beamtentums, Tübingen 1954, S.21, Anm.1.

52 Vgl. Rudolf Braun, Steuern und Staatsfinanzierung als Modernisierungsfaktoren. Ein deutsch-englischer Vergleich, in: Reinhart Koselleck (Hg.), Studien zum Beginn der modernen Welt, Stuttgart 1977, S. 241-262, hier S. 257.

$53 \mathrm{Zu}$ derartigen Entwicklungen kam es seit dem Ausgang des Mittelalters in allen Territorien des Alten Reiches. Vgl. Willowert, Merkmale, S.300f.; ferner Treichel, Primat, S. 26f. 
dienst entschied vielmehr zugleich die fachliche Qualifikation der einzelnen Kandidaten mit ${ }^{54}$. Erste Schritte zur Schaffung einer Leistungskriterien verpflichteten Amtsdienerschaft leiteten die Fürsten im 18. Jahrhundert mit der Errichtung fester Ausbildungswege für die höheren Justiz- und Verwaltungsstellen ein. Seitdem beschränkte sich die Ausbildung der Fürstendiener nicht mehr auf die Absolvierung eines Universitätsstudiums, sondern umfaßte zugleich eine mehrjährige praxisorientierte Vorbereitungszeit in der Verwaltung selbst. Daneben wurden Prüfungsverfahren eingeführt, in denen die Amtsanwärter vor Dienstantritt über ihre persönliche Befähigung Zeugnis abzulegen hatten. Examina gab es zwar auch schon vorher, sie hatten aber eher eine Formalität dargestellt, weil sie »zu einem Initiationsritus vor der Ernennung « 55 entartet waren. Fortan stellten sie die obligatorische Voraussetzung für den Zugang zum Verwaltungsdienst dar. Die bildungspolitischen Neuerungen im Ausleseverfahren wurden durch die verstärkte Beaufsichtigung und verbesserte Alimentierung der Amtsinhaber ergänzt. Diese Maßnahmen zielten in erster Linie darauf, die Bediensteten bei der Wahrnehmung ihrer Pflichten zu disziplinieren; gleichzeitig sollten sie diese aber auch zur Treue gegenüber ihrem Dienstherrn erziehen und langfristig loyale Staatsdiener ${ }^{56}$ aus ihnen machen. Schließlich bildeten sie auch einen gewissen Schutz der Beamten vor der Willkür der Krone ${ }^{57}$.

Der Wirkungsgrad der Reformmaßnahmen war von vornherein begrenzt, weil es hierbei nicht um die völlige Erschließung des Herrschaftsbereiches durch landesherrliche Verwaltungsbehörden ging. Vielmehr handelte es sich um landesherrliche Einzelverfügungen, welche aktuellen Bedürfnissen entsprangen. Gerade auf lokaler Ebene beanspruchten demzufolge Intermediärgewalten, allen voran der Adel, noch immer öffentlich-rechtliche Aufgaben in hohem Maße und schränkten Wirkungsgrad und Handlungsspielraum der fürstlichen Administration beträchtlich ein. Zudem verkehrten sich die von den Monarchen vorgenommenen Neuerungen, die ursprünglich dazu gedacht waren, den Gang der Verwaltung zu vereinfachen, mitunter in ihr Gegenteil: Sie erzeugten ein institutionelles Chaos, bei dem die einzelnen Administrationsorgane ohne klare hierarchische Gliederung, präzise Zuständigkeitsbereiche und genaue Entscheidungsbefugnisse einander konkurrierend gegenüberstanden.

54 Bernd Wunder, Die Rekrutierung der Beamtenschaft in Deutschland. Eine historische Betrachtung, in: Leviathan 5 (1977) S.360-377.

55 Ders., Geschichte, S.37; vgl. auch EngELbrecht, Herzogtum, S.54f.

56 Bis zum Ende des 18. Jahrhunderts war der Begriff des königlichen Bedienten üblich. Erst dann wurde von Staatsdienern gesprochen. Vgl. BonIN, Adel, S.141; WundER, Geschichte, S.27f.; BorCh, Obrigkeit, S. 138; Hansjoachim Henning, Die deutsche Beamtenschaft im 19.Jahrhundert. Zwischen Stand und Beruf, Stuttgart 1984, S.15f.; Otto HiNTzE, Der Beamtenstand, in: DERS., Beamtentum und Bürokratie, hg. von Kersten KRÜGER, Göttingen 1981, S.16-77, hier S. 40 .

57 Willowert, Merkmale, S.352f.; Bernd Wunder, Zum Problem der Kontrolle der Dienerschaft im 18. Jahrhundert, in: Werner Paravicini, Karl Ferdinand Werner (Hg.), Histoire comparée de l'administration (IVe-XVIII' ${ }^{e}$ siècles), München 1980, S.182-187. 
Eine Ausnahme innerhalb der Territoriallandschaft des Großherzogtums stellten die ehemals alt- und neupreußischen Besitzungen dar, auf die zum Zeitpunkt der größten Ausdehnung des Großherzogtums Berg immerhin mehr als die Hälfte des Staatsgebietes entfiel ${ }^{58}$. Was in den nichtpreußischen Gebieten ad hoc und punktuell erfolgte, geschah in den hohenzollernschen Territorien planvoll und flächendeckend. Während der Ausgang der Veränderungen bei den nichtpreußischen Provinzen nahezu offenblieb, war die Entwicklung in den preußischen Landesteilen weitgehend vorgegeben. Spätestens seit der Herrschaft Friedrich Wilhelms I. konzentrierte man sich in der Hohenzollernmonarchie darauf, die Administration der einzelnen Provinzen dem Verwaltungsapparat der preußischen Kernlande anzugleichen eine Politik, die in beschleunigter Form auch in den nach 1800 hinzugewonnenen Entschädigungsländern verfolgt wurde und die im übrigen dem späteren Vorgehen Frankreichs im Großherzogtum ähnelte. Auf allen Ebenen der Administration fand in den Provinzen daraufhin ein Austausch zwischen altständischen Verwaltungsbehörden und preußischen Einrichtungen statt, wobei die säkularisierten Gebiete in nur wenigen Jahren das bewältigten, was in den altpreußischen Territorien mehrerer Jahrzehnte bedurft hat$\mathrm{te}^{59}$. Mit der Reorganisation der Provinzialverwaltungen nach preußischem Vorbild ging es Berlin zum ersten um die Erfüllung der militärischen und fiskalischen Zielvorgaben, zum zweiten um die Integration der einzelnen Provinzen in den preußischen Staatsverband und zum dritten um die Beaufsichtigung und Kontrolle der nur schwer zugänglichen unteren Bereiche der Territorien, um die Intensivierung der landesherrlichen Präsenz in der Provinz und letztlich um die Konsolidierung Preußens als Staatsverband insgesamt.

\subsection{Nichtpreußische Provinzen}

In den nichtpreußischen Provinzen zerfielen die höheren Verwaltungsorgane grundsätzlich in den dreigliedrigen, kollegial organisierten Behördenzug altständischer Prägung: den Geheimen Rat oder die Regierungskanzlei, die Hof-

58 Im Jahre 1808 entfielen etwa $9640 \mathrm{~km}^{2}$, d.h. ca. $56 \%$ der gesamten Fläche des Großherzogtums, auf die ehemals preußischen Gebiete. Angaben nach Demian, Statistik, S.53f.; ENGELBRECHT, Herzogtum, S.19.

59 Jüngere Arbeiten zur preußischen Behördenreorganisation im 18. Jahrhundert: BuRG, Verwaltung, S.63f.; Braun, Steuern, S.247f.; Heinrich HefFTer, Die deutsche Selbstverwaltung im 19.Jahrhundert. Geschichte der Ideen und Institutionen, Stuttgart 21969, S.27f.; Bonin, Adel, S.147f.; ferner Gottfried NiedHaRT, Aufgeklärter Absolutismus oder Rationalisierung der Herrschaft, in: ZHF 6 (1979) S. 199-211. Immer noch von Bedeutung sind folgende ältere Arbeiten: Fritz HarTung, Deutsche Verfassungsgeschichte vom 15.Jahrhundert bis zur Gegenwart, Leipzig, Berlin 1933, S.66f.; Gustav ScHmoller, PreuBische Verfassungs-, Verwaltungs- und Finanzgeschichte, Berlin 1921, S. 133f.; HinTzE, Militär- und Beamtenstaat, S. 47f. 
kammer und das Hofgericht, auch Justizkanzlei genannt ${ }^{60}$. Der Geheime Rat war in der Regel sowohl für sämtliche die allgemeine Verwaltung betreffende als auch für auswärtige Angelegenheiten zuständig. Die Hofkammer verwaltete die Kameraleinkünfte und kümmerte sich um wirtschaftliche Angelegenheiten. Dem Hofgericht oblag die Rechtsprechung in Zivil- und Kriminaljustiz. Es urteilte erstinstanzlich über die Privilegierten und in zweiter Instanz über die Appellationssachen der Untergerichte ${ }^{61}$. In den kleineren Territorien war die institutionelle Auffächerung der Oberbehörden wegen fehlender finanzieller oder personeller Ressourcen häufig noch nicht so weit fortgeschritten. Insbesondere die Bereiche von Justiz und Verwaltung wurden dort immer noch, wie in Rheina-Wolbeck ${ }^{62}$, Dortmund ${ }^{63}$, Gimborn-Neustadt ${ }^{64}$ und Broich $^{65}$ von einer Person oder Institution erledigt. In den größeren Fürstentümern war das Behördenwesen durch die Herauslösung von Fachbehörden dagegen bereits weiter verzweigt ${ }^{66}$. Allerdings waren die Zuständigkeiten deshalb nicht

60 LahrKamp, Die französische Zeit, S.14, 17; Georg Droege, Die Territorien am Mittelund Niederrhein, in: Jeserich u.a., Deutsche Verwaltungsgeschichte, S.690-720, hier S.738. Zur Genese der altständischen Behördenorganisation allgemein: WiLLowEIT, Merkmale, S. 300f.; Treichel, Primat, S.26f.; HaRTung, Verfassungsgeschichte, S. 48f.

61 Als höhere Instanzen dienten zum Teil auswärtige Juristenfakultäten und die Reichsgerichte, so etwa in Rheda und Limburg. Vgl. Précis de l'organisation judiciaire actuelle du Grand-Duché de Berg, o.D., Art.10f., HStAD, GB, Nr. 6244.

62 Josef TönSMEYER, Vom Landesfürstentum Rheina-Wolbeck zur Gutsherrschaft RheineBentlage, hg. von Hans Dieter TöNSMEYER, Rheine/Westf. 1980, S.114f., 149; KocHENDöRFFER, Territorialentwicklung, S. 118.

63 Die Regierung wurde unmittelbar nach der Herrschaftsübernahme durch den oranischen Fürsten als oberste Verwaltungsbehörde eingerichtet. Sie arbeitete zugleich als mittlere Justizbehörde zwischen den höheren Gerichtshöfen und dem Dortmunder Stadtgericht. Vgl. HStAD, GB, Nr.6244; Schambach, Stadtbürgertum, S. 40.

${ }^{64}$ Emil DösSELER, Die oberbergische Wirtschaft und soziale Struktur bis zum Beginn des 19. Jahrhunderts, in: ZBGV 84 (1968/1969) S.49-158, hier S.54.

65 Die Unterherrschaft Broich war bei der Ausübung der Verwaltungsgeschäfte sowie der Gerichtsbarkeit in erster Instanz von ihrem bergischen Lehnsherrn unabhängig. Die bergischen Gerichtshöfe dienten als Berufungsinstanzen. Vgl. Vollmer, Anspruch, S. 243, 246; ferner Otto R. Reduich, Mülheim an der Ruhr. Seine Geschichte von den Anfängen bis zum Uebergang an Preußen 1815, Mülheim a.d. Ruhr 1939, S.308f.

${ }^{66}$ Beispielsweise umfaßten die Oberbehörden der nassau-oranischen Erbländer Siegen, Dillenburg und Hadamar neben der Behördentrias, hier bezeichnet als Landesregierung, Justizkanzlei und Rentkammer, noch zwei Sonderbehörden: ein Oberkonsistorium für Kirchenangelegenheiten und Schulwesen sowie eine Berg- und Hüttenkommission. Veranlaßt durch die hinzugewonnenen säkularisierten und mediatisierten Gebiete richtete der nassau-oranische Prinz nach 1803 außerdem einen Geheimen Rat für die innen- und außenpolitischen Angelegenheiten der oranischen Länder in Fulda und ein Oberappellationsgericht als höchsten Gerichtshof in Hadamar ein. Vgl. Précis de l'organisation judiciaire actuelle du Grand-Duché de Berg, o.D., Art.13f., HStAD, GB, Nr.6244; Paul SchlrTzer, Verwaltungsreform in der Oranierzeit, in: Fuldaer Geschichtsblätter 57 (1981) S. 1-13, hier S. 4; Uwe Zuber, Staat und Kirche im Wandel. Fulda von 1752 bis 1830, Darmstadt, Marburg 1993, S. 181; Hans PhILIPPI, Der oberrheinische Kreis, in: JeSERICH u.a., Deutsche Verwaltungsgeschichte, S. 634-658, hier S.653; Treichel, Primat, S. 38. 
unbedingt klarer geregelt. Da mit der institutionellen Vervielfältigung zumeist keine eindeutige Trennung der Aufgabenbereiche einherging, trug die Auffächerung der Behörden oftmals nicht zur Klärung, sondern im Gegenteil zur Verwischung der Grenzen zwischen den Kompetenzen der einzelnen Verwaltungsorgane bei $^{67}$.

Besonders unübersichtlich sahen die Verhältnisse im Herzogtum Berg aus. Das Eigentümliche der Entwicklung des Herzogtums war hierbei, daß es zunächst zu Modernisierungsansätzen kam, diese aber kurze Zeit später teilweise wieder rückgängig gemacht wurden. Zu Beginn des 19. Jahrhunderts löste die Münchner Regierung unter der Führung von Staatsminister Maximilian Joseph von Montgelas ${ }^{68}$ die bergischen Oberbehörden mitsamt den Sonderkommissionen und Kommissariaten aus der bestehenden Behördentrias heraus, paßte sie der bayerischen Organisationsstruktur ${ }^{69}$ an und vereinigte sie zu einer Landesdirektion ${ }^{70}$, um den unüberschaubar gewordenen Behördenapparat transparenter und das Verwaltungshandeln effektiver zu machen. Zusammen mit der Umformung des altständischen Behördenzugs regelte die Regierung außerdem die Dienstverhältnisse des höheren Verwaltungspersonals durch verschiedene Maßnahmen neu: Die Unterscheidung zwischen adeligen und gelehrten Räten wurde aufgehoben ${ }^{71}$. Alle Bediensteten der höheren Behörden mußten fortan Uniformen tragen ${ }^{72}$. Darüber hinaus erhielten die höheren Justizdiener eine bessere Besoldung, mußten aber im Gegenzug auf beträchtliche Sportelneinnahmen verzichten ${ }^{73}$. Nachdem der Schwager des

${ }^{67}$ Nur vereinzelt waren die verschiedenen Aufgabenbereiche klar voneinander getrennt. Einen solchen Fall stellten die nassau-usingischen Zentralbehörden in Wiesbaden dar, denen die ehemals kurkölnischen Gebiete Deutz, Vilich und Königswinter nach der Säkularisation untergeordnet worden waren. Durch die Übernahme sämtlicher politischer Aufgabenfelder rückte die Landesregierung an die Spitze des bis dahin weitgehend gleichrangigen Behördenzugs, der neben der Regierung noch ein Hofgericht, eine Hofkammer und ein Konsistorium umfaßte. Vgl. Treichel, Primat, S. 44, 46.

68 Zur Figur Montgelas' siehe WEis, Montgelas II.

${ }^{69}$ Die durch Montgelas in Bayern initiierten Verwaltungsreformen waren zum Teil preußischen Vorbildern entlehnt. Vgl. KNEMEYer, Regierungs- und Verwaltungsreformen, S. 195f.

70 Diese zerfiel in zwei Deputationen: Die erste umfaßte den Geheimen Rat, die zweite die Hofkammer, den 1778 gebildeten Geheimen Steuerrat sowie das seit 1792 bestehende Oberforst- und Jagdamt. Das Consilium medicum wurde aufgelöst; der Hofrat und das Oberappellationsgericht - letzteres war nach dem Erhalt des Privilegs de non appelando im Jahre 1769 als Ersatz für die Reichsgerichte eingerichtet worden - bestanden als höhere Gerichtshöfe fort. Zur Zusammensetzung der bergischen Oberbehörden vor $1800 \mathrm{vgl}$. Max Bär, Die Behördenverfassung der Rheinprovinz seit 1815, Bonn 1919 (ND 1965), S. 38f.; ENGELBRECHT, Herzogtum, S.61f., 215f.

71 Ibid. S. 148, 161.

72 Ibid. S.161f;; allgemein zur Einführung von Uniformen für Verwaltungsdiener siehe Wunder, Geschichte, S. $40 \mathrm{f}$.

${ }^{73}$ Die »Haupt-Landespragmatik über die Dienstverhältnisse der Staatsdiener«, die in Bayern seit dem 1.Januar 1805 Geltung besaß, trat im Herzogtum Berg jedoch nicht in Kraft. Zur Reform der Amtsdienerschaft im Herzogtum Berg vgl. ENGELBRECHT, Herzogtum, S.157f.; ferner Ders., Führungsschichten, S.68f. 
bayerischen Kurfürsten, Herzog Wilhelm von Bayern, am 20. November 1803 das Herzogtum Berg als Apanage erhalten hatte, machte die Münchner Regierung jedoch die nur zwei Jahre zuvor eingeleitete Reform der Oberbehörden bis auf die modifizierten Rekrutierungskriterien für das Hofratspersonal sowie die rechtliche Gleichstellung von Bürgertum und Adel in landesherrlichen Diensten wieder rückgängig ${ }^{74}$. Die Behörden kehrten daraufhin weitgehend zu ihrer ursprünglichen Arbeitsweise zurück ${ }^{75}$. Hinterlassenschaft dieser halbherzigen Politik war ein enormer Reformstau im Innern, der das Großherzogtum Berg als Nachfolgestaat erheblich vorbelastete. Personne n'étant chargé exclusivement et en titre d'aucune partie, bemängelte Finanzminister Agar Ende März 1806, chacun cherchant probablement à éloigner le travail qui ne lui convenait pas, ou à devenir le rapporteur des affaires aux quelles il s'interessait [sic], aucune branche ne fut dirigée avec assez de suite et de régularité 76 .

Unterhalb der Landesbehörden waren in den nichtpreußischen Territorien allerorts die bis ins Mittelalter zurückreichenden Amtsverfassungen unverändert in Kraft ${ }^{77}$. Formal liefen darin sämtliche Geschäftszweige in der Person des Amtmannes oder Drosten zusammen ${ }^{78}$. In seiner Hand lag die Leitung der gesamten Verwaltung; daneben besaß er jurisdiktionelle Befugnisse namentlich durch das Amtsverhör ${ }^{79}$. Ihm zur Seite stand eine Reihe landesherrlicher Amts-

74 Ders., Herzogtum, S.224.

75 Allerdings ergaben sich in der Verfassungswirklichkeit Vorrangstellungen zwischen den einzelnen Institutionen, weil der bergische Geheime Rat auf Kosten der übrigen Behörden Aufgaben an sich zog und zudem durch die verbreitete Gewohnheit der Ämterkumulation sein Gewicht stärken konnte. Die Räte des Oberappellationsgerichts waren nämlich zugleich Mitglieder des Geheimen Rats. Vgl. ibid. S. 64f.

76 Undatiertes Tableau de l'administration civile et judiciaire des duchés de Clèves et de Berg sous le régime prussien (März 1806), angefertigt von Agar, AN, AF IV 1225.

77 Die Amtsverfassungen sind in der historischen Forschung bisher nur wenig untersucht worden. Auf dieses Defizit weist vor allem Treichel, Primat, S.28, Anm.21, hin. Carl-August AgEndA, Der Amtmann im 17. und 18. Jahrhundert. Ein Beitrag zur Geschichte des Richter- und Beamtentums, Diss. jur. Göttingen 1972, und Joachim EıBACH, Der Staat vor Ort: Amtmänner und Bürger im 19. Jahrhundert am Beispiel Badens, Frankfurt a. M., New York 1994, beschäftigten sich eingehend mit den Amtmannstellen. Zur Amtsverfassung am Niederrhein vgl. DROEGE, Territorien, S.695f.; WALZ, Stände, S. 165f.; zur Herkunft der Amtsverfassungen allgemein siehe Peter BlickLE, Formes de l'administration paysanne autonome en Europe centrale, 1400-1800, in: Paravicini, Werner, Histoire comparé, S.392-404, hier S.399.

78 In Siegen und Hadamar waren im Jahre 1744 Amtskollegien zur Verbesserung von Verwaltung und Justiz eingerichtet, aber auf Druck aus der Bevölkerung 1774 wieder aufgelöst worden. Die Amtmänner kehrten daraufhin in ihre alten Verwaltungsbezirke zurück. Vgl. Norbert ZaBEL, Räumliche Behördenorganisation im Herzogtum Nassau (1806-1866), Wiesbaden 1981, S. 28f.; PhilipPI, Kreis, S. 653; Treichel, Primat, S. 38f.

79 Guido RoтthоF, Gerichtswesen und Rechtsordnungen, in: Kurköln. Land unter dem Krummstab. Essays und Dokumente, hg. vom Nordrhein-Westfälischen Staatsarchiv Düsseldorf u. a., Kevelaer 1985, S.257-264, hier S.260; Norbert ANDERNACH, Die landesherrliche Verwaltung, in: ibid. S.241-250, hier S.245; ENGELBRECHT, Herzogtum, S.70f.; Heinz Rosenthal, Solingen. Geschichte einer Stadt, Bd.2: Von 1700 bis zur Mitte des 19. Jahrhunderts, Duisburg 1972, S.42; Lenzen, Beyträge, Bd. 1, Düsseldorf 1802, S.16; Justus voN 
diener, die unter anderem Aufgaben im Rahmen der Rechtspflege und der Domänen- bzw. Steuerverwaltung erledigten ${ }^{80}$. Zum Beispiel waren im Herzogtum Berg Richter, Obersteuereinnehmer, Kellner und Gerichtsschreiber neben den Amtsmännern tätig. In den nassau-oranischen Fürstentümern Siegen, Dillenburg und Hadamar traten Amtleute, Rentmeister, Amtsaktuare und mitunter Weihermeister hinzu ${ }^{81}$. Bei der Ausübung der Rechtsprechung konkurrierten Amtmann und Richter mit den Patrimonialherren, deren Gerichtsbarkeit durch die Rheinbundakte expressis verbis bestätigt worden war ${ }^{82}$.

Der Amtmann gehörte meist dem Adel an, weil die Ritterschaft ihr Recht behauptet hatte, die finanziell einträglichen Amtmannstellen durch Mitglieder aus den eigenen Reihen zu besetzen ${ }^{83}$. Das bergische Doppelamt Hückeswagen-Bornefeld blieb von 1676 bis 1806 dabei durchgehend in der Hand einer Familie $^{84}$. Aufgrund seiner adeligen Herkunft kam dem Amtmann im Unterschied zu den übrigen, in der Regel bürgerlichen Amtsträgern eine Doppelfunktion zu. Als Bediensteter des Landesherrn mußte er diesen vor Ort vertreten. Als Mitglied des ritterbürtigen Adels war er gleichzeitig ständischer Vertreter. Während die Amtmannstellen weitgehend in adeliger Hand lagen, wurden die eigentlichen Amtsgeschäfte größtenteils nicht mehr von den Amtmännern selbst, sondern von bürgerlichen Fürstendienern geleitet. In Nassau-Oranien hatten landesherrliche Kellner mehr und mehr die Aufgaben der Amtleute übernommen ${ }^{85}$, in den kurkölnischen Ämtern und im Herzogtum Berg ${ }^{86}$ war die Verwaltung sogar ganz auf die bürgerlichen Amtsverwalter übergegangen.

GRUNER, »Wallfahrt zur Ruhe und Hoffnung « (1802), in: Bergische Forschungen 15 (1978) S.131-145, hier S.139; Müller, Bürgerproteste, S.101; Alois SALER, Die Lage der Bauern in Nassau-Oranien im 18. Jahrhundert, in: Nassauische Annalen 57 (1937) S. 1-53, hier S.5. 80 Die Ämter bildeten gemeinsam mit den landesherrlichen Untergerichten die erste Instanz. Die Appellationen der Ämter gingen in zweiter Instanz an die höheren Gerichte. Im Herzogtum Berg war dafür in der Regel der Hofrat zuständig. Vgl. ENGELBRECHT, Herzogtum, S.70f; Rosenthal, Geschichte, S. 42; Vollmer, Anspruch, S.243; Saler, Lage, S. 5.

81 Siehe LenzeN, Beyträge, Bd.1, S.16f.; Walz, Stände, S. 165; BÄr, Behördenverfassung, S.39; ENGelbrecht, Herzogtum, S.70f.; Saler, Lage, S. 5.

82 Artikel 27 der Rheinbundakte; Clercq, Recueil, S. 177.

83 Eine Ausnahme hiervon bildete das Amt Deutz in Kurköln, wo die Amtmannstellen nicht dem Adel vorbehalten waren. Siehe ANDERNACH, Verwaltung, S.245.

84 Es wurde von der ritterbürtigen Familie von Nagel besetzt. Vgl. Karl Wilhelm HeUSER, Die Amtmänner von Nagel und ihre Familien. Ein Beitrag zur Geschichte der Ämter Hückeswagen und Bornefeld, in: Romerike Berge 18 (1968/1969) S.22-32.

85 PhIl IPPI, Kreis, S. 653.

86 ENGELbrecht, Herzogtum, S.70f.; ANDERNACH, Verwaltung, S. 245; Bär, Behördenverfassung, S.28. Vgl. auch das von Agar verfaßte undatierte Tableau de l'administration civile et judiciaire des duchés de Clèves et de Berg sous le régime prussien (März 1806), AN, AF IV 1225. Agar kritisierte darin, daß an der Spitze der bergischen Ämter jeweils ein Adeliger stand, qui jamais n'y réside, qui presque toujours $\grave{a}$ [sic] d'autres emplois, et qui s'occupe peu soit de l'administration, soit de l'exercice des attributions de justice et de police qui lui sont confiées. C'est cependant à ces baillis que doivent être adressés tous les ordres, toutes les dispositions administratives et leur devoir serait d'en surveiller l'exécution. Uniques intermediaires [...] entre l'autorité supérieure et les agens [sic] établis pour la régie et la 
Die bürgerlichen Bediensteten und nicht mehr die adeligen Amtmänner trugen deshalb die eigentliche Last der Lokalverwaltung. Die Amtmannstellen entwickelten sich auf diese Weise zu reinen Sinekuren ${ }^{87}$.

Diese Entwicklungen führten zur Verdichtung der Landesherrschaft und damit zur Stärkung des monarchischen Einflusses in den Ämtern ${ }^{88}$, bewirkten aber auch, daß Amtsmißbrauch und Korruption in den Amtsverwaltungen zunahmen. Viele der landesherrlichen Bediensteten erhielten nämlich nur eine geringfügige Besoldung und waren gezwungen, sich ihren Lebensunterhalt über Zusatzeinkünfte, unter anderem über Tätigkeiten in der Rechtspflege, zu sichern. In manchen Fällen, wie etwa im Herzogtum Berg, mußten sie für die Ausübung ihres Amts überdies hohe Pachtsummen entrichten. Exzessive Geldeintreibungen und Bestechungen gerade im Bereich der Justiz gehörten daher zur Tagesordnung und sorgten besonders in den Städten des Herzogtums, in denen die von den fürstlichen Amtsverwaltern ausgeübten Funktionen von den städtischen Einwohnern zunehmend auch als Eingriff in korporative Rechte verstanden wurden, immer mehr für Unmut, Spannungen und Konflikte ${ }^{89}$.

Die Landesregierungen waren sich der Reformbedürftigkeit der Amtsverfassungen durchaus bewußt und leiteten auch vereinzelt Schritte ein, um die neuralgischen Punkte der Amtsverfassungen, allen voran die ungleichförmige Bezirkseinteilung sowie die Trennung von Administration und Justiz, zu beseitigen. Aber ihre Reformabsichten gelangten zumeist über das Planungsstadium nicht hinaus. Im Herzogtum Berg scheiterte die Umgestaltung der Amtsverfassungen, für die seit 1801 ein ausgearbeiteter Organisationsentwurf vorlag, an der bayerischen Regierung ${ }^{90}$. In Nassau-Oranien vereitelte dagegen die Bevölkerung Veränderungsmaßnahmen ${ }^{91}$.

Was für die Ämter galt, traf ebenso für die städtischen Körperschaften zu. Hier herrschten ebenfalls anachronistische Zustände. Auch hier bestand zwischen überlieferter Rechtsordnung und Verfassungswirklichkeit eine große Kluft. Formal stellten viele Städte der nichtpreußischen Provinzen nach wie vor autonome Korporationen dar. Auf der Grundlage tradierter Rechte leite-

perception des revenus publics, leur absence ou leur négligence laisse les intérêts du prince et de l'état à la discrétion de ces nombreux préposés.

87 Das galt namentlich für das Herzogtum Berg. Vgl. ENGELBRECHT, Herzogtum, S.73; HEUSER, Amtmänner, S. 29.

88 Siehe unter anderem die Auseinandersetzungen zwischen Amtmann und Untertanen in der Unterherrschaft Broich. REDLICH, Mülheim, S.303, 305f.; MÜLlER, Bürgerproteste, S. 104f.

89 Die Amtsverwalter wurden deshalb auch als "die Pest der Rechtspflege « bezeichnet. Zit. nach EnGELbrecht, Herzogtum, S.71. Zu den Mißständen in den bergischen Ämtern allgemein siehe Gruner, »Wallfahrt«, S.139; Heuser, Amtmänner, S.29f.; Müller, Bürgerproteste, S. $99 f$.

90 Engelbrecht, Herzogtum, S.219f. Wie groß das in der Bevölkerung angestaute Konfliktpotential war, bringt ein anonymes Spottgedicht auf die Figur des Amtmannes vom 23. Oktober 1786 zum Ausdruck. Vgl. HStAD, JB, Hofrat A, Nr.274.

91 PhilipPI, Kreis, S. 653; Treichel, Primat, S. 38f. 
ten sie sämtliche Angelegenheiten im Finanz-, Verwaltungs- und Justizbereich selbständig. Wie in den Ämtern befand sich die Geschäftsführung in der Hand einer altständisch verwurzelten Behörde: dem Stadtmagistrat. Dieser wurde von den Bürgern der Städte, d.h. von all jenen, die das Bürgerrecht erworben hatten, im jährlichen Turnus gewählt.

Faktisch waren jedoch auch die städtischen Verfassungsstrukturen vielerorts abgeschliffen. Das Wahlverfahren hatte längst seinen genossenschaftlichen Charakter verloren. Ausschlaggebend für den Eintritt in den Magistrat war nicht mehr das Votum der abstimmungsberechtigten Bürger. Vielmehr wurde die Wahl schon im vorhinein durch die Zugehörigkeit zu einem eng begrenzten Kreis an Familien entschieden. Nicht persönliche Eignung, sondern soziale Herkunft beherrschte somit das Rekrutierungsverfahren. Darüber hinaus waren viele Städte unter landesherrliche Kuratel geraten und hatten dadurch erheblich an Autonomie eingebüßt' ${ }^{92}$. In Kaiserswerth beispielsweise wurde 1768 das Wahlrecht der Bürgerschaft wie auch der Aufgabenbereich der Magistrate von der kurfürstlichen Regierung beträchtlich eingeschränkt. Der großherzoglich-bergische Provinzialrat von Düsseldorf konstatierte vor diesem Hintergrund am 15. September 1807, der Kaiserswerther Magistrat stelle nur noch einen Schatten-Magistrat ${ }^{93}$ dar. In Gerresheim übernahm 1775 ein Bürgermeister die Aufgaben des aufgehobenen Magistrats. Ihm standen hierbei mehrere Unterbeamte zur Seite ${ }^{94}$. Geringe Autonomie besaß ebenfalls der Düsseldorfer Magistrat, der sich mehrheitlich aus dem Kreis der fürstlichen Dienerschaft rekrutierte. Landesherrliche Eingriffe gehörten auch hier zur Tagesordnung ${ }^{95}$.

Der Abbau kommunaler Selbstverwaltungsrechte in den Städten beschleunigte sich nach 1803, als der Wegfall der ständischen Barrieren nach der Säkularisation und Mediatisierung in einigen Gebieten die ungehinderte Durchführung von Reformen möglich machte ${ }^{96}$. Besonders eindrucksvoll war diese

92 Das galt insbesondere für die Finanzen und die Magistratswahlen. Zum Verlust städtischer Autonomierechte in den deutschen Territorialstädten allgemein: Klaus GERTEIs, Die deutschen Städte in der frühen Neuzeit. Zur Vorgeschichte der »bürgerlichen Welt«, Darmstadt 1986, S.71f.

93 Schreiben des Düsseldorfer Provinzialrats an den Innenminister vom 15. September 1807, HStAD, GB, Nr. 12437.

$94 \mathrm{Vgl}$. Klaus MülLER, Unter pfalz-neuburgischer und pfalz-bayerischer Herrschaft (1614-1806), in: Hugo WeIDENhaUPT (Hg.), Düsseldorf. Geschichte von den Ursprüngen bis ins 20. Jahrhundert, Bd.2: Von der Residenzstadt zur Beamtenstadt (1614-1900), Düsseldorf 21990, S. 7-312, hier S. 95; ferner Heinz-Karl Junk, Zum Städtewesen im Großherzogtum Berg (1806-1813), in: Helmut NaunIN ( $\mathrm{Hg}$.), Städteordnungen des 19. Jahrhunderts. Beiträge zur Kommunalgeschichte Mittel- und Westeuropas, Köln, Wien 1984, S.272-305, hier S. 279 .

95 Müller, Herrschaft, S.90f.; Ders., Bürgerproteste, S. 105f.; ENGELBRECHT, Herzogtum, S. $72 f$.

96 Im vormaligen Vest Recklinghausen verloren die Städte mit Übernahme der französischen Verwaltungsstrukturen nach 1806 ihre einstige Selbständigkeit und mußten insbesondere auf ihr Wahlrecht verzichten. Im Fürstentum Rheina-Wolbeck behielten die Ma- 
Entwicklung in der ehemaligen Reichsstadt Dortmund, wo der nassau-oranische Fürst den bestehenden Stadtmagistrat, wie bereits erwähnt, mit einem Federstrich durch einen wesentlich verkleinerten und von ihm ernannten Magistrat ersetzte. Allerdings erfolgten die Umbrüche selbst in Dortmund nur mit Konzessionen an die bestehenden Verhältnisse. Die städtische Administration wurde dem landesherrlichen Verwaltungsapparat inkorporiert; die Magistratsverfassung bestand dagegen in nuce fort. Zudem herrschte in personeller Hinsicht Kontinuität, denn die städtischen Bediensteten setzten sich überwiegend aus Mitgliedern des vormaligen Magistrats zusammen ${ }^{97}$.

Während viele Magistrate in den Sog der Landesherrschaft gerieten, blieb eine Anzahl von Städten von landesherrlichen Interventionen weitgehend verschont. Ganz besonders traf dies auf die Städte des Herzogtums Berg zu, in denen die Stadtbewohner ihre Unzufriedenheit über die städtischen Verhältnisse seit den 1780er Jahren mehr und mehr offen bekundeten und Reformen einklagten ${ }^{98}$. Verdrossenheit zeigten vor allem jene Bevölkerungskreise, die ihre Belange in den Magistraten nicht oder nicht mehr vertreten sahen: die Gruppe der Kaufleute, Unternehmer und Zunfthandwerker. Der wachsende Mißmut der städtischen Bevölkerung über die maroden Verfassungsstrukturen in den Städten sorgte zunehmend für Spannungen und entwickelte sich, katalysiert durch die Vorgänge inner- und außerhalb Frankreichs am Ausgang des 18. Jahrhunderts, förmlich zu einer "Partizipationskrise «99. Die bergischen Kaufleute scherten aus der Verfassung aus und gründeten zur Durchsetzung ihrer Anliegen eigene Interessenvertretungen ${ }^{100}$. Vereinzelt kam es zu Aufruhr und Protesten ${ }^{101}$. Die Forderungen, die in den Reihen der Aufständischen hierbei gestellt wurden, richteten sich auf die Reaktivierung des genossenschaftlichen Charakters der Städte und auf die Wiederherstellung der städtischen Autonomie. Sie waren somit in erster Linie rückwärtsgewandt und

gistrate zwar ihre Selbstverwaltungsrechte weitgehend, gerieten aber ebenfalls unter landesherrliche Aufsicht. Vgl. BETTE, Recklinghausen, S. 29; Adolf DoRIDER, Geschichte der Stadt Recklinghausen in den neueren Jahrhunderten (1577-1933), Recklinghausen 1955, S. 65f.; TöNSMEYER, Landesfürstentum, S.84f.

97 SсHAMвасH, Stadtbürgertum, S. 40f.

98 Klaus MülLER, Städtische Unruhen im Rheinland des späten 18. Jahrhunderts, in: RhVjBII 54 (1993) S. 164-187; ENGELBRECHT, Herzogtum, S.97. Es galt ebenso für die Städte der nassau-oranischen Altlande und der ehemaligen Grafschaften Steinfurt und Bentheim. Vgl. den Bericht des Siegener Stadtmagistrats an den Dillenburger Provinzialrat vom 6. November 1807, HStAD, GB, Nr.4492; ferner das Schreiben des Steinfurter Provinzialrats an den Innenminister vom 24. Januar 1808, HStAD, GB, Nr. 4495; ferner FinKEMEYER, Verfassung, S.74f.

99 Engelarecht, Herzogtum, S. 97.

100 Ibid. S. $245 f$.

$101 \mathrm{Zu}$ Unruhen und Protestaktionen kam es namentlich in Solingen, Elberfeld, Broich und Düsseldorf. In Solingen handelte es sich zunächst um einen Subsistenzprotest. Vgl. Müller, Bürgerproteste, S.95f.; Heinz Rosenthal, Aufruhr in Solingen 1795, in: Anker und Schwert 1 (1959) S.149-162; DerS., Geschichte, S. 189f.; siehe ferner das Protokoll des Herzoglichen Hofgerichts vom 5. August 1805, HStAD, GB, Nr. 4567. 
erfolgten mit dem Ziel, eine als gerecht verstandene Ordnung zu verteidigen. Revolutionäre Absichten verbanden sich damit nicht. Von den revolutionären Vorgängen in Frankreich blieben die Proteste sogar nahezu unbeeinflußt. Französisches Gedankengut diente, wenn überhaupt, nur als Träger traditioneller Ordnungsvorstellungen und wurde rezipiert, um den eigenen Argumenten mehr Schlagkraft und Legitimation zu verleihen ${ }^{102}$.

Tatsächlich gaben die zum Teil scharfen Auseinandersetzungen in den bergischen Städten einen entscheidenden Anstoß dafür, daß die Münchner Regierung erste Schritte zur Umgestaltung des städtischen Ordnungsgefüges einleitete ${ }^{103}$. Die von bayerischer Seite in Angriff genommenen Planungen zur Neuordnung der Stadtverfassungen standen dabei in krassem Gegensatz zu dem, was die Aufständischen gefordert hatten. Sie richteten sich nicht auf die Stärkung der Städte, sondern auf die definitive Verankerung der Landesherrschaft im kommunalen Bereich. Allerdings wurde die geplante Reform nicht mehr verwirklicht. Statt dessen setzte die bayerische Regierung ihre Politik fort, jene Magistratsverfassungen zu reorganisieren, die nicht durch den Hauptrezeß aus dem 17.Jahrhundert gesichert waren ${ }^{104}$. Die altständischen Stadtverfassungen einschließlich ihrer beträchtlichen Mängel und Schwächen überdauerten so letztlich vielerorts die bayerische Herrschaft ${ }^{105}$. Mit ihren Bemühungen hatte die Münchner Zentrale jedoch allemal zu erkennen gege-

102 MülLER, Bürgerproteste, S. 103. Die Auseinandersetzungen in den bergischen Städten befanden sich durchaus auf einer Linie mit den Konflikten und Protestaktionen, die in anderen deutschen Territorien am Ende des 18. Jahrhunderts ausbrachen. Siehe u. a. die Beiträge in dem Sammelband von Berding, Soziale Unruhen; GerTEIS, Städte, S. 83f.; Anke Bethmann, Revolutionsrezeption und -gestaltung in Schaumburg - Politische Öffentlichkeit als Indikator des Demokratisierungsprozesses - 1789 und 1848: Das Bürgertum betritt die politische Bühne, in: Hubert Höıng (Hg.), Vom Ständestaat zur freiheitlich-demokratischen Republik. Etappen in Schaumburg, Melle 1995, S.79-105, hier S. 83f.; Elisabeth FeHRENBACH, Bäuerlicher Widerstand und ländliche Gesellschaft zur Zeit der Französischen Revolution, in: Peter Hütrengerger, Hansgeorg Molrtor (Hg.), Franzosen und Deutsche am Rhein 1789 - 1918 - 1945, Essen 1989, S. 83-89; ENGELBRECHT, Herzogtum, S. $97 f$.

103 Sie forderte den bergischen Geheimen Rat dazu auf, Vorschläge zur Reformierung der bergischen Magistrate zu machen. Schreiben der Münchner Regierung an die bergische Landesdirektion vom 25. August 1802, in: LA Speyer, A7, Nr.53; Müller, Herrschaft, S.111.

104 Am 4. März 1806 hob sie die Magistrate von Gräfrath und Burg mit der Begründung auf, daß in Landstädten, so weit der Hauptreceß nicht entgegen steht und nicht ganz besondere, erhebliche Umstände eintreten, keine Magistrate weiter belassen werden sollen. Die Gerichtsbarkeit ging auf das Amt Solingen über. Der Bürgermeister wurde künftig vom Amtmann auf Vorschlag des Gerichts ernannt. Er war zugleich Schöffe. Landesherrliche Verfügung vom 4. März 1806, HStAD, JB, Hofrat A, Nr.179a; vgl. auch Müller, Das Haus, S. 18f.

105 Das verdeutlichen eindringlich die aus dem Jahre 1805 stammenden und nach Übergang des Herzogtums an Frankreich wiederholt vorgebrachten Vorschläge zur Reformierung des Düsseldorfer Magistrats mit dem Titel »Mémoire et Extrait d'un livre déjà présenté au Roi de Bavière concernant l'organisation du Magistrat de Dusseldorf« (Vorschläge eines Unpartheiischen zu einer zweckmäßigeren Einrichtung des Düsseldorfer 
ben, daß an der grundsätzlichen Neuordnung der städtischen Verfassungsverhältnisse kein Weg vorbeiführte.

\subsection{Preußische Provinzen}

In den alt- und neupreußischen Provinzen setzten sich die Oberbehörden, dem Vorbild der Kernlande entsprechend, aus zwei Gliedern zusammen - den Kriegs- und Domänenkammern auf der einen und den Regierungen auf der anderen Seite ${ }^{106}$. Kammern und Regierungen bildeten reine Mittelinstanzen zwischen der Berliner Zentrale und den Unterbehörden und besaßen als solche nur mehr regionalen Charakter. Wie die Landesbehörden in den nichtpreußischen Provinzen waren sie kollegial verfaßt. Die Rekrutierung ihrer Mitglieder erfolgte im Unterschied zu diesen allerdings allein auf Grundlage fachlicher Kriterien ${ }^{107}$.

Kammern und Regierungen besaßen klar umrissene Aufgabenbereiche ${ }^{108}$. Die Kammern waren verantwortlich für militärische Angelegenheiten, die Verwaltung der fürstlichen Einkünfte und die Steuererhebung, das Armen-, Kirchen- und Schulwesen sowie für Hoheitssachen. Zusätzlich oblag ihnen die innere Polizeiverwaltung ${ }^{109}$. Damit übernahmen sie das Gros der von den alt-

Magistrats und besseren Verwaltung der städtischen Einkünfte, 1805), HStAD, GB, Nr. 4425; zum Scheitern der Städtereform in Berg siehe auch MülLER, Herrschaft, S.111.

106 Während die Regierungen nominell an Vorläuferinstitutionen anknüpften, waren die Kammern neue Einrichtungen. 1723 entstand in Berlin das General-Ober-Finanz-Kriegsund Domänen-Direktorium, das bei der Einrichtung der Kriegs- und Domänenkammern als Vorbild diente. Zur Reorganisation der preußischen Zentral- und Provinzialbehörden siehe Walther Hubatsch, Verwaltungsentwicklung von 1713-1803, in: JeSERICH u. a., Deutsche Verwaltungsgeschichte, S.892-911, hier S.895f.; Schmoller, Finanzgeschichte, S. 134f.; HINTZE, Militär- und Beamtenstaat, S.47f.

107 Die Pflicht zur Absolvierung einer praktischen Vorbereitungszeit und zur Ablegung von Examina bestand für Justizdiener seit 1755 und für Verwaltungsdiener seit 1770 . Vgl. Wunder, Rekrutierung, S.361; Ders., Geschichte, S.37f.; Kloosterhuis, Fürsten, S.150; Burg, Verwaltung, S. 163, 165; Hintze, Beamtenstand, S. 39; Schmoller, Finanzgeschichte, S.161; ferner Adolf Klein, Justus Bockemühl (Hg.), 1770-1815 Weltgeschichte am Rhein erlebt. Erinnerungen des Rheinländers Christoph Wilhelm Henrich Sethe aus der Zeit des europäischen Umbruchs, Köln 1973, S.26.

108 Die gleichförmige Organisationsstruktur verhinderte indes auch hier nicht, daß in den Kriegs- und Domänenkammern zu Münster und Hamm Sonderkommissionen fortlebten bzw. neue Verwaltungszweige entstanden. So konnten in Münster die Sonderbehörden für die Medizinal- und für die Universitätsverwaltung überdauern. Der Zuständigkeitsbereich des Medizinalkollegiums wurde allerdings vergrößert und auf Tecklenburg und Lingen ausgedehnt. In Hamm sonderten sich aus der Kammer Verwaltungszweige für das Salzwesen, die Fabriken, das Medizinalwesen, die Forsten und die Wege aus. LaHRKamp, Münster, S. 167; KochenDöRFFER, Territorialentwicklung, S. 116; Franz BöcKENHOLT, Zur Geschichte der königlich-preußischen Provinzialverwaltungsbehörde der ehemaligen Grafschaft Mark zu Hamm (Westf.), Münster 1912, S.71, 134f.; BURG, Verwaltung, S. $19 f ., 110$.

109 Undatiertes Tableau de l'administration civile et judiciaire des duchés de Clèves et de Berg sous le régime prussien (März 1806), angefertigt von Agar, AN, AF IV 1225; Böckenholr, Geschichte, S. 70; Eva-Maria SchöNBACH, Preußische Verwaltung, politischer 
ständischen Organen ehemals erledigten Arbeit ${ }^{110}$. Die Regierungen kümmerten sich demgegenüber ausschließlich um die Rechtsprechung, dies aber im weitläufigsten Sinne ${ }^{111}$. Administration und Justiz waren demzufolge sorgfältig voneinander geschieden - eine Maßnahme, für die im übrigen nicht die Organisationsstrukturen der preußischen Hauptlande ${ }^{112}$, sondern die in Ansbach-Bayreuth durchgesetzten Reformen Pate standen ${ }^{113}$.

In den an Murat gefallenen preußischen Gebieten gab es jeweils zwei Kammern und zwei Regierungen. Die erste Kammer hatte ihren Sitz in Hamm ${ }^{114}$. Sie war 1787 gebildet worden und ursprünglich nur für die Grafschaft Mark verantwortlich gewesen. Nach den Besitzverschiebungen auf dem linken Rheinufer wurde sie zugleich zuständig für den rechtsrheinischen Teil des Herzogtums Kleve sowie die säkularisierten Abteien Essen, Elten und Werden ${ }^{115}$. Eine zweite Kriegs- und Domänenkammer wurde nach den Landgewinnen im Jahre 1803 in Münster eingerichtet und von der französischen Interimsregierung von 1806 bis 1808 unter dem Titel »Collège administratif« beibehalten.

Umbruch und die Anfänge der Moderne (1787-1847), in: Wilhelm RibHEgGe (Hg.), Geschichte der Stadt und Region Hamm im 19. und 20.Jahrhundert, Düsseldorf 1991, S.11-71, hier S.16; BuRg, Verwaltung, S.110; LAHrKamp, Münster, S. 158.

110 Nicht weniger als $40 \%$ aller niederrheinischen und westfälischen Kammerräte rekrutierten sich durchschnittlich aus dem Adel. BoniN, Adel, S.149; zur sozialen Zusammensetzung der preußischen Kammern vgl. zudem BurG, Verwaltung, S. 161f.

111 Die Regierung zu Münster bestand aus dem Instruktionssenat, dem Oberappellationssenat und dem Kriminalsenat. Der erste leitete die administrative Justiz, erkannte über Privilegierte und über die Appellationen gegen Erkenntnisse der Untergerichte. Der zweite befand in zweiter Instanz über die Appellationen gegen die Erkenntnisse des Instruktionssenats und in dritter Instanz über die Revision gegen die Appellationserkenntnisse des Instruktionssenats, der dritte entschied in Strafsachen. Dabei bildete die Regierung das Mittelglied zwischen den Untergerichten in den Territorien und dem Geheimen Obertribunal in Berlin. In Fragen, die die Justizverwaltung betrafen, unterstand sie dem dortigen Geheimen Etatrat. Vgl. Précis de l'organisation judiciaire actuelle du Grand-Duché de Berg, o.D., Art.5f., HStAD, GB, Nr.6244; KochendörfFer, Territorialentwicklung, S.113; LahrKamp, Münster, S. 169f.; Kloosterhuis, Fürsten, S.150.

$112 \mathrm{Zu}$ den preußischen Provinzialbehörden allgemein: HaRTung, Verfassungsgeschichte, S.70f.; SCHMoller, Finanzgeschichte, S. 142f.; Otto HinTZE, Der Commissarius und seine Bedeutung in der allgemeinen Verwaltungsgeschichte, in: Ders., Beamtentum, S.78-112, hier S.80f.

113 Verantwortlich war dafür die Übernahme des fränkischen Ressortreglements aus dem Jahre 1797. Der Hammer Kammer ging demzufolge die von ihr bis dahin ausgeübte Kammerjustiz verloren. Vgl. LAHRKaMp, Münster, S.158; BuRG, Verwaltung, S.109f.; SchöNвасH, Verwaltung, S.16; BöcKenHolt, Geschichte, S.70, 134. Zu den Veränderungen in Ansbach-Bayreuth allgemein: KNEMEYER, Regierungs- und Verwaltungsreformen, S. 191f. 114 Sie behielt im Gegensatz zur Kriegs- und Domänenkammer in Münster während der französischen Besatzung von 1806 bis 1808 ihren preußischen Titel. KOCHENDÖRFFER, Territorialentwicklung, S. 151 .

115 Zur Kriegs- und Domänenkammer in Hamm siehe BöckenHolt, Geschichte, S.38f.; Burg, Verwaltung, S.38; SchönbaCH, Verwaltung, S. 14; RotherT, Absolutismus, S. 296f.; KochendörFFER, Territorialentwicklung, S.132f.; HARTLIEB voN WALLTHOR, Eingliederung, S.236f. 
Sie war zuständig für die säkularisierten Gebiete des Erbfürstentums Münster sowie die altpreußischen Provinzen Tecklenburg und Lingen ${ }^{116}$. Parallel zu den beiden Kammern gab es zwei Regierungen in Lingen und Münster ${ }^{117}$. Die erste bestand seit 1722 und kümmerte sich um die altpreußischen Provinzen Tecklenburg und Lingen ${ }^{118}$. Die Regierung zu Münster wurde demgegenüber zusammen mit der Schaffung der dortigen Kriegs- und Domänenkammer eingerichtet und war sowohl für die altpreußischen Provinzen Mark, Kleve und Lippstadt als auch für die neu hinzugekommenen säkularisierten Gebiete Münster, Essen, Elten und Werden zuständig ${ }^{119}$. Das Gebiet, um das sie sich zu kümmern hatte, war damit nicht nur erheblich größer als das der Lingener Einrichtung. Es erstreckte sich zudem auf beide Kammerbezirke.

Entwicklungsunterschiede zwischen preußischen und nichtpreußischen Territorien gab es auch auf den unteren Verwaltungsebenen. Während in den nichtpreußischen Gebieten noch überall die Amtsverfassung Geltung hatte, war in den preußischen Provinzen die ostelbische Kreisverfassung in Kraft. In den altpreußischen Ländern war diese im Verlauf des 18. Jahrhunderts eingeführt worden. In den westfälischen Neuerwerbungen wurde die Kreisverfassung in Kraft gesetzt, nachdem diese bereits zu Beginn des 19. Jahrhunderts an das Haus Hohenzollern übergegangen waren ${ }^{120}$. Wie bei den höheren Administrationskollegien bestanden zwischen den Organen der Ämter und den Kreisbehörden kaum mehr Gemeinsamkeiten. Eine Parallele zur Amtsverfassung stellte zwar die Figur des mit den Kreisgeschäften beauftragten Landrats dar ${ }^{121}$. Wie der adelige Amtmann oder Drost war dieser nämlich königlicher Bediensteter und ständischer Vertrauensmann zugleich. Das Landratsamt blieb daher, nicht anders als es in vielen anderen Territorien für die Amtmänner der Fall war, der eingesessenen Ritterschaft vorbehalten ${ }^{122}$. Das Präsentationsrecht der Landratskandidaten oblag den Kreisständen, die Ernennung erfolgte durch

116 KochendörfFer, Territorialentwicklung, S. 112; LAHRKAmp, Münster, S.157; HaRTLIEB voN WALLTHOR, Eingliederung, S. 240.

$117 \mathrm{Zu}$ den Vorläuferinstitutionen siehe BuRG, Verwaltung, S. 103f; KLoosterhuis, Fürsten, S. $147 \mathrm{f}$.

118 Zur Entwicklung der Regierung in Lingen siehe HunSche, Landkreis, S. 27, 37f.; KoCHENDÖRFFER, Territorialentwicklung, S.136f.

119 Hartlieb von Wallthor, Eingliederung, S.240; LahrKamp, Münster, S.157; KochenDÖRFFER, Territorialentwicklung, S.113.

1201734 wurden Tecklenburg und Lingen, 1753 Kleve und Mark in Kreise eingeteilt. Tecklenburg und Lingen bildeten einen gemeinsamen Kreis, Kleve zerfiel bei seinem Abfall an Murat noch in zwei, die Mark in vier Kreise. In Münster trat die Landratseinteilung am 1.Juni 1806 in Kraft, d.h. erst kurz vor der Besetzung des Landes durch Frankreich. Es zerfiel in vier Kreise. Vgl. HuNsche, Landkreis, S.32; BuRG, Verwaltung, S. 67f.; RoTHERT, Absolutismus, S.302f., 306; KochendöRFFER, Territorialverwaltung, S.113; HARTLIEB voN WALLTHOR, Eingliederung, S.237, 241.

121 Zum Landratsamt vgl. u. a. BonIN, Adel, S.153f.; BURG, S. 67; Vierhaus, Ständewesen, S.351; Schmoller, Finanzgeschichte, S.153f.; HaRTUnG, Verfassungsgeschichte, S.72; HintZe, Militär- und Beamtenstaat, S.47f.

122 Bonin, Adel, S. 154f.; Burg, Verwaltung, S. 166. 
den Monarchen ${ }^{123}$. Im Gegensatz zu den Amtmannstellen war das Landratsamt jedoch nicht mehr Pfründe, sondern berufliche Hauptbeschäftigung. Außerdem kümmerte sich der Landrat ausschließlich um militärische und polizeiliche Angelegenheiten, die gleichmäßige Verteilung der Lasten, die Überwachung der Lokalbehörden und den Vollzug königlicher Verordnungen, übte aber keinerlei Aufgaben in der Rechtsprechung aus ${ }^{124}$. Die Justiz lag überwiegend in der Hand geprüfter und fest besoldeter Landrichter, die in erster Instanz über alle zivilen Angelegenheiten urteilten - fiskalische Sachen und privilegierte Personen ausgenommen ${ }^{125}$. Ein weiteres Strukturmerkmal der Kreisverfassung war die Abgrenzung der Städte vom platten Land, die es in den Ämtern nicht gab. Sie resultierte aus der fiskalischen Trennung von Stadt und Land in der preußischen Steuerverfassung. In der Stadt wurde eine Akzise erhoben, auf dem Land eine Kontribution. Daraus ergab sich zwangsläufig eine Zweiteilung des Verwaltungsapparats. Die Landräte waren für die Kontribution zuständig. Um die Akziseerhebung in den Städten kümmerten sich dagegen sogenannte Stadträte, wobei jeweils ein Commissarius loci in einem mehrere Städte umfassenden Steuerbezirk tätig war ${ }^{126}$. Im Unterschied zu den Landräten handelten diese Kommissare ausschließlich im Auftrag des preußischen Königs. Dem entsprach, daß sie in der Regel nicht dem Adel entstammten $^{127}$. Neben der Überwachung der Steuererhebung in den Städten bestand ihre Hauptaufgabe darin, die städtischen Finanzen und die allgemeine Führung der städtischen Verwaltungsgeschäfte zu beaufsichtigen. Darüber hinaus sollten sie Wirtschaft, Handel und Gewerbe in den Städten fördern.

Für die Städte war die Einführung der Akziseverfassung mit erheblichen Einbrüchen in die kommunale Selbstverwaltung verbunden ${ }^{128}$, zumal die Berliner Regierung es nicht bei dieser Maßnahme beließ, sondern die Durchsetzung der preußischen Steuerverfassung zum $A$ nla $B$ nahm, um die genossenschaftlichen, wenn auch häufig zerrütteten Strukturen der Stadtverfassungen weiter abzutragen $^{129}$. Statt die städtischen Verwaltungsgeschäfte einem selbst gewählten Rat

123 Bonin, Adel, S. 154; Hunsche, Landkreis, S.33f.

124 Hartung, Verfassungsgeschichte, S. 72; Agenda, Amtmann, S. 13.

125 Sie arbeiteten entweder nach dem Kollegialprinzip oder bestanden aus einem Richter und einem Aktuar. Vgl. den Vortrag der Hofräte Richter und Ganterweiler als klevische Beamte über die bisherige klevische Justizverfassung vom 13. August 1806 sowie die Bemerkungen des Hofrats Schmitz dazu, HStAD, GB, Nr. 6242; Précis de l'organisation judiciaire actuelle du Grand-Duché de Berg, o.D., Art. 6, HStAD, GB, Nr. 6244.

126 Zum preußischen Steuerrat vgl. ReinHard, Besonderheiten, S. 78f.; HarTUNG, Verfassungsgeschichte, S. 72; HiNTzE, Militär- und Beamtenstaat, S.48.

127 Burg, Verwaltung, S.166.

128 Der Handlungsspielraum der Städte wurde nicht nur durch die Steuerräte, sondern zunehmend auch durch Fabrikenkommissare eingeengt. Vgl. REINHARDT, Besonderheiten, S. 83.

129 Aus der umfangreichen Literatur zu den preußischen Städtereformen im 18. Jahrhundert befassen sich folgende Arbeiten konkret mit Städten der dem Großherzogtum einverleibten alt- und neupreußischen Gebiete: Stievermann, Preußen, S.9f.; Reinhard, 
zu überlassen, vertraute sie diese überall einem zeitlich unbefristeten und erheblich verkleinerten Magistrat an. Die Ersternennung der Magistratsmitglieder erfolgte zumeist durch den Monarchen, anschließend sollten sich die Räte kooptieren. Die personellen Entscheidungen blieben aber weiterhin von der Zustimmung des Monarchen abhängig ${ }^{130}$. Neben der Umwandlung der Ratswahl in ein Kooptationsverfahren schmälerte die Regierung die Autonomie der Städte durch die sukzessive Umwandlung der bis dahin gewählten und entscheidungsbefugten Bürgerschaftsvertretungen in landesherrliche Organe ohne politisches Mitspracherecht ${ }^{131}$. Als Bestandteil der städtischen Verwaltung blieben diese allerdings ebenso bestehen wie die Magistratsverfassungen ${ }^{132}$.

So tiefgreifend die Umwälzungen in den preußischen Provinzen auch waren - zur vollständigen Anpassung der Randgebiete an die Kernlande kam es auch hier nicht ${ }^{133}$, weil dazu entweder nicht die Zeit reichte, was in den säkularisierten Gebieten häufig der Fall war ${ }^{134}$, oder aber auf lokale Traditionen

Besonderheiten, S.71f., 115f.; Karl EmsBach, Politische Geschichte in der Stadt Wesel 1666-1815, in: Geschichte der Stadt Wesel, Bd. 1, Düsseldorf 1991, S. 251-307, hier S.280f.; Wilfried ReIninghaus, Die Stadt Iserlohn und ihre Kaufleute (1700-1815), Dortmund 1995, S. 464f.; Ders., Wirkung, S. 169; Susanne KILl, Vom alten Münster zur preußischen Provinzialhauptstadt (1780-1816), in: Lothar GaLl (Hg.), Vom alten zum neuen Bürgertum. Die mitteleuropäische Stadt im Umbruch 1780-1820, München 1991, S.105-141; LAHRKAMr, Münster, S. 287f.; Matthias M. EsTER, Kontinuität und Wandel zwischen fürstbischöflicher, französischer und preußischer Zeit. Politische Führungsschichten sowie Stadtverfassung und Stadtverwaltung in Warendorf im frühen 19. Jahrhundert, in: Warendorfer Schriften 11/12 (1981/1982) S.7-55, hier S. 25f.; Karl LERCH, Die frühe Neuzeit (ca. 1550-1830), in: Ludger HeID u. a. (Hg.), Kleine Geschichte der Stadt Duisburg, Duisburg 1983, S.109-184, hier S.135f.; Willy Trmm, Die Stadtwerdung Hagens und die preußische Städtereform des 18. Jahrhunderts in der Grafschaft Mark, Hagen 1975.

130 Das galt für jene Magistrate, die vor Aufhebung der Ratswahlen durch Friedrich Wilhelm I. das Wahlrecht besessen hatten. Vgl. Stievermann, Preußen, S. 20; Reinhard, Besonderheiten, S. 124.

131 Ausführlich dazu ibid. S. 103f.

132 Die Bewertung der preußischen Städtereformen im 18. Jahrhundert ist in der jüngeren Geschichtsforschung nach wie vor umstritten. REINHARDT, Besonderheiten, S. 129f., beispielsweise gelangt für die Städte der Grafschaft Mark zu dem Schluß, die preußischen Maßnahmen hätten primär die Verfassungsnorm der Verfassungswirklichkeit angepaßt und keineswegs die wirkliche Beseitigung der Stadtverfassung zum Ziel gehabt. Seiner Meinung nach überwogen daher auch die Kontinuitätslinien, auch wenn durch die Aufhebung des Wahlcharakters der Magistrate erheblich in die städtische Selbstverwaltung eingegriffen worden sei. Demgegenüber sieht Stievermann, Preußen, S.23f., in den Reformen eher eine Zäsur.

133 Beispiel dafür war die Rechtskodifikation des Allgemeinen Landrechts für die Preußischen Staaten. So waren zum Beispiel in den Kommunen die Verhältnisse und Rechte [...] hauptsächlich nach den bey ihrer Errichtung geschlossenen Verträgen, oder ergangenen Stiftungsbriefen; nach den vom Staate erhaltenen Privilegien und Concessionen; und nach den auch in der Folge unter Genehmigung des Staats abgefaßten Schlüssen zu beurtheilen. ALR, II, 6, Art. 26.

134 Die Berliner Regierung wollte bei der Übertragung der preußischen Verwaltungsinstitutionen auf die säkularisierten Gebiete nichts überstürzen und unterzog die örtlichen Verhältnisse zunächst einer sorgfältigen Bestandsaufnahme. Erst in einem zweiten Schritt ließ 
oder Besonderheiten Rücksicht genommen wurde ${ }^{135}$. Überreste der altständischen Ordnung blieben demzufolge erhalten oder fanden im nachhinein wieder Eingang in die neue Verwaltung ${ }^{136}$. Das führte zwangsläufig zu strukturellen Unterschieden und mitunter zu regionalen, teilweise sogar zu lokalen Sonderentwicklungen ${ }^{137}$.

Konzessionen an das altständische Verfassungsgefüge machte die Berliner Regierung insbesondere bei Einführung der Kreisverfassung in den Provinzen Kleve und Mark. Da es in keiner der beiden Provinzen Kreisstände gab und somit die Körperschaft fehlte, welche die Landratsstellen zu besetzen hatte ${ }^{138}$, beauftragte die Regierung kurzerhand die Ritterkurien damit, zwei bis drei habile, ritterbürtige, im Kreise angesessene Subjecte zur Landratsbedienung in Vorschlag zu bringen ${ }^{139}$. Damit nahm sie in Kauf, daß der dem Landratsamt

sie prüfen, inwiefern die vorliegenden Behörden mit den neuen Institutionen in Einklang zu bringen waren. Durch die Langwierigkeit der Vorarbeiten wie auch die nur kurze Zugehörigkeit Münsters zur hohenzollernschen Dynastie gelangten die Absichten zur Übernahme der preußischen Steuerverfassung über das Planungsstadium nicht hinaus. Die Städte Münsters unterstanden demzufolge den Landräten. Siehe HarTlieb von WALLTHOR, Eingliederung, S. 241; Ester, Kontinuität, S. 30; LAHRKamp, Die französische Zeit, S. 16.

135 Rücksichtnahme auf lokale Traditionen und Besonderheiten war ein wesentliches Element der nach Einheit und Zentralisierung strebenden Politik Preußens. Vgl. die Aussage Otto HauSERS, Grundsätze preußischer Integrationspolitik, in: BaUmGART, Expansion und Integration, S. 475-486, hier S.476, die von preußischer Seite verfolgte Integrationspolitik sei nicht »schematische Gleichmacherei « gewesen, sondern habe sich »um einen Ausgleich zwischen den allgemeinen Staatsnotwendigkeiten und der Schonung der speziellen Eigentümlichkeiten « bemüht.

136 Vor allem aus diesem Grund werden die preußischen Reformen vor 1800 in der historischen Forschung nur unter beträchtlichen Vorbehalten mit den Reformen zu Beginn des 19. Jahrhunderts in einen genealogischen Zusammenhang gestellt. So plädiert Barbara VOGEL, Die »allgemeine Gewerbefreiheit « als bürokratische Modernisierungsstrategie in Preußen. Eine Problemskizze zur Reformpolitik Hardenbergs, in: Dirk Stegmann u.a. (Hg.), Industrielle Gesellschaft und politisches System. Beiträge zur politischen Sozialgeschichte. Festschrift für Fritz Fischer, Bonn 1978, S. 59-78, hier S.69f., dafür, die preußische Reformzeit bereits Mitte der 1790er Jahre beginnen zu lassen, warnt aber davor, die preußische Reformbereitschaft vor 1806 überzubetonen. Ähnlich argumentiert Peter BAUMGarT, Epochen der preußischen Monarchie im 18.Jahrhundert, in: ZHF 6 (1979) S. 287-315. Auch NiPPERDEY, Geschichte, S.33, unterstreicht in erster Linie die Grenzen preußischer Reformpolitik im 18. Jahrhundert. Demgegenüber weist GoRISSEN, Steuerreform, S.212, am Fall der Grafschaft Mark die weichenstellende Bedeutung der preußischen Reformen des 19. Jahrhunderts im ökonomischen Bereich nach. Vgl. ferner Otto Hintze, Preußische Reformbestrebungen vor 1806, in: Ders., Regierung und Verwaltung, hg. von Gerhard Oestreich, Göttingen 1967, S.504-529.

137 Sie wirkten mitunter auf die preußischen Hauptlande zurück. Vgl. Wolfgang KöLLMaNN, Der Freiherr vom Stein in der Grafschaft Mark, in: Heimatbuch Hagen + Mark 22 (1981) S. 20-38; LichthardT, Studien, S. 121f;; HefFTer, Selbstverwaltung, S.77f.

138 Adolf ScHILl, Die Einführung des Landratsamts in Cleve-Mark, in: Forschungen zur Brandenburgischen und Preußischen Geschichte 22 (1909) S.1-54, hier S.25f.; HARTLIEB von Wallthor, Eingliederung, S.237; RotherT, Absolutismus, S. 302.

139 Zit. nach SchILL, Einführung, S.23. Diese Regelung galt im übrigen beinahe für die gesamte preußische Monarchie. Vgl. BonIs, Adel, S.154; RotherT, Absolutismus, S. 302; LichthaRdT, Studien, S. 36; Hunsche, Landkreis, S. 33f. 
inhärente lokale Vertretungsanspruch in Kleve und Mark zumindest formal verlorenging. Aufgrund des Widerstandes der märkischen Bevölkerung gegen die Einführung der Akzise ${ }^{140}$ beschloß die preußische Regierung zudem nachträglich, in der Grafschaft Mark die Steuerverfassung den örtlichen Besonderheiten anzupassen und die auf die Agrar- und Gewerbeverhältnisse KernpreuBens zugeschnittene steuerrechtliche Trennung von gewerblichen und nichtgewerblichen Gebieten, die man bis dahin in der Grafschaft nicht gekannt hatte, zumindest teilweise aufzugeben. Die Akzise sollte künftig von Stadt und Land gemeinsam aufgebracht werden - eine Regelung, durch welche in der Grafschaft eine Sonderentwicklung eingeleitet und diese zugleich zum »Experimentierfeld « ${ }^{141}$ der preußischen Monarchie gemacht wurde. Parallel dazu belebte die preußische Regierung die alten Verwaltungseinheiten, die Ämter und Kirchspiele, wieder ${ }^{142}$, denn neben Akzisebevollmächtigten der Städte wurden ebenfalls Deputierte der Amts- und Erbentage für die Klärung der Repartitionsfrage zwischen Stadt und Land herangezogen ${ }^{143}$. Wie bei den Landständen geschah der Rekurs auf kommunale Abgeordnete allerdings nur unter Vorbehalten. Der König folgte damit primär pragmatischen Erwägungen der Durchführbarkeit, wollte aber keineswegs die Mitspracherechte der Kommunen stär$k^{144}$. Dennoch schuf er auf diese Weise eine wesentliche Grundlage dafür, daß die Beteiligung von Kommunalorganen an der Provinzialverwaltung in der Grafschaft Mark bis zum Ende der preußischen Herrschaft konstitutiv blieb ${ }^{145}$.

Entgegenkommen zeigte die preußische Regierung auch gegenüber den Städten ${ }^{146}$. Beispielsweise stattete sie die Bürgerschaftsvertretungen der märkischen Städte Schwelm und Iserlohn auf Druck der dortigen Einwohnerschaft mit umfassenden politischen Mitwirkungsmöglichkeiten aus ${ }^{147}$. Ebenso gewährte sie der ehemaligen Bürgerschaftsvertretung der Stadt Münster nach

140 Um dem Akzisezwang auszuweichen, gingen viele Einwohner der Grafschaft zum Schmuggel über oder ließen sich mit ihrem Gewerbe auf dem Land nieder. Die Steuererträge erreichten daher bei weitem nicht das, was man sich in Berlin erhofft hatte.

141 Reininghaus, Wirkung, S. 169.

142 Schill, Einführung, S.27f.; Lichthardt, Studien, S.118f.; RotherT, Absolutismus, S.302; HARTLieb von Wallthor, Eingliederung, S. 237.

143 Zur preußischen Akzisepolitik in der Grafschaft Mark siehe ReININGHaus, Wirkung, S. 148f.; Gorissen, Steuerreform, S.190f.; StievermanN, Preußen, S.11f.,19; Burg, Verwaltung, S.66f.; RotherT, Absolutismus, S.308f.

144 GoRISSEN, Steuerreform, S. 209.

145 Vgl. ibid. S.210, Anm.92. Dort werden die an der Steuerverteilung mitwirkenden Grundeigentümer als regionale Notabeln bezeichnet, weil sie sowohl ökonomisch bedeutsam als auch politisch wirksam wurden.

146 Die Möglichkeit dazu ergab sich aus der Tatsache, daß es keine allgemein gültige Städteordnung gab, sondern die einzelnen städtischen Magistratsreglements und die Bestimmungen des ALR gesetzliche Grundlage für die Verhältnisse in den Städten waren. Vgl. REINHARDT, Besonderheiten, S.125f.

147 Auch in diesem Punkt besaß die Grafschaft Mark daher durchaus zukunftsweisenden Charakter. Vgl. ibid., S.127; Reininghaus, Iserlohn, S. 462f.; DerS., Wirkung, S. 169; StIEvermanN, Preußen, S.23. 
Einführung des preußischen Magistrats de facto weiterhin ihre einstigen Mitspracherechte ${ }^{148}$. Neben den Konzessionen im Bereich der politischen Mitsprache billigte die preußische Regierung, daß viele Stadträte weiterhin Funktionen in der Rechtsprechung wahrnahmen ${ }^{149}$. Nur vereinzelt, und das galt vornehmlich in Städten der säkularisierten Gebiete, wie Münster, Essen und Werden, bildete sie die Magistrate zu reinen Verwaltungsorganen um, schmolz bestehende Gerichte zusammen ${ }^{150}$ und übertrug die Justizangelegenheiten einem eigens dafür eingerichteten landesherrlichen Gericht ${ }^{151}$. Überhaupt wurde die Zweigliedrigkeit der Behörden in Justiz- und Verwaltungsorgane nirgendwo strikt eingehalten und konkurrierten die Sondergerichte der Zwischengewalten immer noch mit den landesherrlichen Tribunalen ${ }^{152}$, wenn auch in eingeschränkter Form und unter staatlicher Aufsicht ${ }^{153}$. Insgesamt stellten daher selbst die aus preußischem Besitz stammenden Provinzen des Großherzogtums keine homogenen und von der Herrschaft vollständig durchdrungenen Territorien dar ${ }^{154}$.

\section{Wirtschaft und Gesellschaft}

Im Jahre 1808, zum Zeitpunkt seiner größten territorialen Ausdehnung, besaß das Großherzogtum Berg annähernd 900000 Einwohner ${ }^{155}$. Etwa 418000 Ein-

148 LahrKamp, Münster, S. 298.

149 Précis de l'organisation judiciaire actuelle du Grand-Duché de Berg, o.D., Art.6, HStAD, GB, Nr. 6244; Stievermann, Preußen, S. 20; Ester, Kontinuität, S. 30f.; EmSBach, Geschichte, S. 280. Die Stadt Soest konnte darüber hinaus Mitspracherechte im Finanzwesen bewahren. Siehe REINHARDT, Besonderheiten, S. 119f.

150 In Münster fielen dadurch allein drei Untergerichte fort. LAHRKamp, Münster, S. 171; RoTHERT, Absolutismus, S. 313.

151 Reinhardt, Besonderheiten, S.121; Brand, Geschichte, S. 12; LaHRKamp, Münster, S. 294; KoCHENDÖRFFER, Territorialentwicklung, S. 115.

152 In Lippstadt konkurrierten beispielsweise die preußischen und lippe-detmoldschen Gerichte auch weiterhin bei Appellationen des Stadtgerichts. Précis de l'organisation judiciaire actuelle du Grand-Duché de Berg, o.D., Art.9, HStAD, GB, Nr.6244. Zum Fortbestand der geistlichen Gerichtsbarkeit in Münster vgl. LaHRKAMP, Münster, S.171f.

153 Das galt namentlich für die Richter der Patrimonialjustiz. Sie hatten darüber hinaus den Qualifikationsanforderungen des preußischen Königs zu entsprechen. Précis de l'organisation judiciaire actuelle du Grand-Duché de Berg, o.D., Art.6, HStAD, GB, Nr. 6244; BuRg, Verwaltung, S.109f.; Schmoller, Finanzgeschichte, S. 161; HARTUNG, Verfassungsgeschichte, S.75.

154 Das von Vertretern der borussophilen Historiographie des Kaiserreichs, allen voran von Gustav Schmoller und Otto Hintze aufgestellte Paradigma von der herausragenden Bedeutung Preußens für den Staatsbildungsprozeß ist in der historischen Forschung inzwischen weitgehend widerlegt. Vgl. BLÄNKNER, "Absolutismus «, S. 52f.; ferner WUNDER, Geschichte, S. 17.

155 Wie die Flächenangabe ist auch die Einwohnerzahl des Großherzogtums in den Quellen schwer zu eruieren. Als Grundlage dienen an dieser Stelle die Angaben von ScHMIDT, Grand-Duche, S. 24, Anm.2, S. 482. 
wohner, d.h. beinahe die Hälfte der Bevölkerung, lebten in den ehemals preuBischen Territorien ${ }^{156}$. Das Gebiet des vormaligen Herzogtums Berg umfaßte rund 265000 , die nassau-oranischen Länder besaßen 80000 , die übrigen mediatisierten Duodezfürstentümer insgesamt ungefähr 137000 Bewohner ${ }^{157}$. Infolge der Gebietsverluste in den anschließenden Jahren sank die Bevölkerung des Großherzogtums auf 780000 Einwohner ${ }^{158}$.

Die christlichen Religionen waren zahlenmäßig nahezu gleichmäßig vertreten. Etwas mehr als die Hälfte aller Einwohner gehörte im Jahre 1808 der katholischen Religion an, $24 \%$ waren lutherischen, $21 \%$ reformierten Glaubens. Daneben gab es eine kleine jüdische Minderheit ${ }^{159}$. Regional variierte die konfessionelle Zugehörigkeit beträchtlich. In den ehemals preuBischen Gebieten überwog der lutherische Glaube. In den Ländern des Prinzen von Nassau-Oranien setzte sich die Bevölkerung mehrheitlich aus Reformierten zusammen. In den vormaligen Territorien des Fürstbistums Münster im Norden des Großherzogtums dominierte die katholische Religion. Einzig auf dem Gebiet des ehemaligen Herzogtums Berg koexistierten Katholizismus und Protestantismus fast paritätisch, wenn auch mit innerregionalen Unterschieden. Während nahezu die Hälfte der Einwohner der katholischen Kirche angehörte, waren ca. $35 \%$ reformierten und $17 \%$ lutherischen Glaubens. Territoriale Abweichungen bestanden ebenfalls bei der jüdischen Minorität. Beinahe die Hälfte der jüdischen Bevölkerung lebte in den ehemals preußischen Gebieten; die übrigen Juden waren vor allem im Herzogtum Berg, den nassau-oranischen Erbländern und der Grafschaft Steinfurt ansäs$\operatorname{sig}^{160}$.

\subsection{Wirtschafts- und Sozialordnung}

Wie die Strukturen im politisch-administrativen Bereich wurzelten Wirtschaft und Gesellschaft in den einzelnen Territorien fest im agrarisch geprägten, kor-

156 Die Grafschaft Mark stellte mit 197000 Einwohnern die bevölkerungsreichste Landschaft dar, gefolgt von den Gebieten des ehemaligen Erbfürstentums Münster mit 153000, den Grafschaften Lingen und Tecklenburg mit zusammen 55000, dem rechtsrheinischen Teil des Herzogtums Kleve mit $\mathbf{5 1 0 0 0}$ sowie den ehemaligen Abteien Essen, Elten und Werden mit zusammen knapp 22000 Einwohnern.

157 Nach SchмidT, Grand-Duché, S. 482.

158 Bevölkerungsstatistik des Großherzogtums Berg für Februar 1812, AN, AF 642, plaq. 5099; SchmidT, Grand-Duché, S.24, Anm. 2.

159 Zum Zeitpunkt der größten Ausdehnung des Großherzogtums belief sich die Zahl der jüdischen Einwohner auf beinahe 5000. Nach den territorialen Einbußen im Jahre 1810 sank sie auf 3000. Vgl. den Recueil de Renseignements statistiques fournis par le Ministre de l'Intérieur, o. D. (1808/1809), AN, 29 AP 59, ferner den Rapport sur l'etat des Juifs du grand Duché de Berg [sic] des Verwaltungsrats Theodor Joseph Lenzen an Finanzminister Agar (1807/1808), HStAD, GB, Nr.171.

160 Schreiben des Düsseldorfer Staatsrats an den französischen Kaiser vom 28. Oktober 1808, ibid., Nr. 171. 
porativ verfaßten altständischen Ordnungsgefüge ${ }^{161}$. Ein Teil der großherzoglich-bergischen Bevölkerung war nach wie vor ständisch gegliedert und zerfiel in Adel ${ }^{162}$, Klerus, städtisches Bürgertum und Bauernschaft ${ }^{163}$. Der Adel des Großherzogtums bildete hierbei zwei territorienübergreifende, durch vielfältige politische, familiäre und wirtschaftliche Verflechtungen zusammengehaltene Adelslandschaften. Die eine bestand aus dem katholischen Adel der rheinisch-westfälischen Gebiete, die andere umschloß den protestantischen Adel Kleves und der Mark ${ }^{164}$.

Viele Einwohner lebten immer noch auf dem Land und waren eingefaßt in die rechtlichen, wirtschaftlichen und sozialen Strukturen von Grundherrschaft und genossenschaftlicher Landgemeinde. In der Grafschaft Mark waren zu Beginn des 19. Jahrhunderts etwa 70\% der Bevölkerung auf dem Land ansässig, im Fürstentum Siegen $78 \%$ und in Tecklenburg-Lingen sogar $88 \%$. Im gesamten deutschprachigen Raum lag der Durchschnitt bei etwa $75 \%$. Im Großherzogtum gab es insgesamt nur vier Städte mit mehr als 10000 Einwohnern. Die größte von ihnen war die Hauptstadt Düsseldorf mit etwa 20000 Einwohnern. Ihr folgten Münster mit etwa 14000 und Elberfeld, Barmen und Mülheim an der Ruhr mit ca. 12000 Einwohnern ${ }^{165}$.

Hauptnahrungsquelle der ländlichen Bevölkerung war die Landwirtschaft. In den Städten dominierte dagegen das Handwerk, das in der Regel noch zünftisch organisiert war und große Teile der städtischen Einwohnerschaft von der Möglichkeit zur Ausübung eines Handwerks ausklammerte. Allerdings gab es auch auf dem Land zünftisch eingebundes und in den Städten

161 Zur ständischen Gesellschaft siehe u. a. Lothar GALL, Von der ständischen zur bürgerlichen Gesellschaft, München 1993, S.3f., 54f.; Hans-Ulrich Wehler, Deutsche Gesellschaftsgeschichte, Bd.1: Vom Feudalismus des Alten Reichs bis zur Defensiven Modernisierung der Reformära: 1700-1815, München 1987, S.124f.

162 Einzelne Territorien wie die nassau-oranischen Erb- und Indemnisationsländer sowie die Herrschaften Gimborn-Neustadt und Homburg besaßen dagegen nur wenig oder gar keinen landsässigen Adel.

163 Adel und Klerus repräsentierten dabei nur eine Minderheit. So machte der Adel nicht mehr als 1\% der Einwohner aus. Den größten Anteil an der Bevölkerung hatten die Bauern. Vgl. Hans Pohl, Die ständische Gesellschaft, in: Jeserich u. a., Deutsche Verwaltungsgeschichte, S. 244-267, hier S.245; ENGELBRECHT, Herzogtum, S.127.

164 Vgl. ibid. S.132f.; Harm Klueting, Reichsgrafen - Stiftsadel - Landadel. Adel und Adelsgruppen im niederrheinisch-westfälischen Raum im 17. und 18. Jahrhundert, in: Rudolf ENDRES (Hg.), Adel in der Frühneuzeit. Ein regionaler Vergleich, Köln, Wien 1991, S.17-53; Heinz REIF, Westfälischer Adel 1770-1860, Göttingen 1979; SAlER, Lage, S.10f.; Schambach, Stadtbürgertum, S.21; Dösseler, Wirtschaft, S.81; Heckmann, Geschichte, S. 83.

165 Vgl. Junk, Das Großherzogtum, S. 72f.; Gisela LANGE, Das ländliche Gewerbe in der Grafschaft Mark am Vorabend der Industrialisierung, Köln 1976, S. 76; Stefanie ReEKERS, Beiträge zur statistischen Darstellung der gewerblichen Wirtschaft Westfalens um 1800, Teil 7: Wittgenstein und Siegen, in: Westfälische Forschungen 25 (1973) S.59-167, hier S.107; Hans-Ulrich WeHLER, Wirtschaftlicher Wandel in Deutschland 1789-1815, in: Berding u. a., Deutschland und Frankreich, S. 100-135, hier S.102. 
außerzünftisches Handwerk ${ }^{166}$. Soziale Mobilität zwischen den einzelnen Bevölkerungsgruppen war aufgrund vielfältiger Schranken kaum möglich.

Einige Gesellschaftsgruppen lebten seit jeher außerhalb der altständischen Gesellschaft oder waren ihr nur bedingt zugeordnet. Hierzu gehörten zum einen die jüdischen Einwohner ${ }^{167}$. Sie besaßen weder Zugang zur Bürgergemeinde und den Berufskorporationen, noch konnten sie sich uneingeschränkt niederlassen ${ }^{168}$. Darüber hinaus mußten sie bestimmte Sonderabgaben bei religiösen Zeremonien wie Heirat, Geburt und Todesfall entrichten. Als Kompensation für die Ausgrenzung aus der bestehenden Sozialordnung waren sie von der Entrichtung öffentlicher Abgaben befreit und besaßen Vorteile beim Geldverleih ${ }^{169}$. Eine Ausnahme bildeten in diesem Zusammenhang allerdings

166 Friedrich Lenger, Sozialgeschichte der deutschen Handwerker seit 1800, Frankfurt a. M. 1988, S. 13, 29, hat deshalb zu Recht vor einer idealtypischen Betrachtung des Handwerks gewarnt. Vgl. ferner Karl Heinrich KaUfHOLD, Gewerbelandschaften in der frühen Neuzeit (1650-1800), in: Hans PoHL (Hg.), Gewerbe- und Industrielandschaften vom Spätmittelalter bis ins 20. Jahrhundert, Stuttgart 1986, S.112-202, hier S. 189f.; zur Situation des städtischen und ländlichen Handwerks in einzelnen Territorien siehe LANGE, Gewerbe, S. 101f.; LaHRKamp, Münster, S. 499f.

167 Dabei waren in einzelnen Territorien, wie in den nassau-oranischen Erbländern und dem Herzogtum Berg, in der zweiten Hälfte des 18. Jahrhunderts verschiedene Maßnahmen ergriffen worden, um die Lage der dort lebenden Juden zu verbessern. Bei den Reformen handelte es sich um Korrekturen innerhalb der bestehenden Ordnung, wie die Abschaffung des Leibzolls, die Erleichterung der Gewerbeausübung oder die Öffnung christlicher Schulen für jüdische Kinder. Sie richteten sich nicht darauf, die Eingliederung der Juden in die bestehende Gesellschaftsordnung durchzusetzen. Vgl. Johann Joseph Scortr $(\mathrm{Hg}$.), Sammlung der Gesetze und Verordnungen, welche in den ehemaligen Herzogthümern Jülich, Kleve und Berg und in dem vormaligen Großherzogthum Berg über Gegenstände der Landeshoheit, Verfassung, Verwaltung und Rechtspflege ergangen sind. Vom Jahr 1475 bis zu der am 15. April 1815 eingetretenen Königlich Preuß. Landes-Regierung, Zweiter Theil: Vom Jahr 1767 bis zum Jahr 1808 und von Nr. 2001 bis incl. Nr. 3000, Düsseldorf 1821, Nr. 2150, 2773.

168 Um sich niederlassen zu können, waren die jüdischen Einwohner zum Erwerb von Geleitskonzessionen oder Schutzbriefen verpflichtet. Die Höhe der zu zahlenden Summe sowie der Modus der Erneuerung differierten in den einzelnen Herrschaften. Im ehemaligen Herzogtum Berg setzte sich der von den Juden für die Niederlassung zu zahlende Tribut aus einem an die Rentmeisterei einmalig zu leistenden Betrag von 10000 Gulden (nach dem Abtritt Jülichs und der Verpflichtung der Juden zur Leistung der Kontributionssteuer nur noch ein Drittel) und einer jährlich an die Hofkammer in Düsseldorf zu entrichtenden Summe von 4000 Gulden zusammen. Den Betrag trug die gesamte jüdische Gemeinde. Bei der Erneuerung des Schutzbriefes - in der Regel alle sechzehn Jahre - mußte eine Kronensteuer gezahlt werden. Die letzte Erneuerung der Geleitskonzession erfolgte im Herzogtum Berg im Jahre 1779. Siehe den Rapport sur l'etat des Juifs du grand Duché de Berg [sic] des Verwaltungsrats Theodor Joseph Lenzen an Finanzminister Agar (1807/1808), HStAD, GB, Nr. 171; Roв, Regierungsakten des Großherzogtums Berg, S.32f.; Friedrich LAU, Geschichte der Stadt Düsseldorf, Bd. 1: Von den Anfängen bis 1815, Düsseldorf 1921, S.181.

169 Die bergischen Juden konnten beispielsweise freien Handel unabhängig von den Zünften betreiben, Geld mit einem Zinsfuß bis zu 6,25\% verleihen. Daneben besaßen sie die Gerichtsbarkeit der 1. Instanz, waren vom Militärdienst befreit und zahlten nur wenig Ge- 
die bergischen Unterherrschaften, wo die jüdischen Einwohner den Christen weitgehend gleichgestellt waren. Dort genossen sie nicht nur ähnliche Rechte wie die christliche Bevölkerung, sondern trugen ebenfalls zu den öffentlichen Abgaben bei, durften unbewegliches Eigentum erwerben und besaßen Handels- und Gewerbefreiheit. Anstelle eines Leibzolls mußten sie jährlich Schutzgeldzahlungen leisten ${ }^{170}$.

Sozial marginalisiert waren zum anderen die landarmen und landlosen Unterschichten. Hierbei handelte es sich um einen äußerst heterogenen Personenkreis, dessen Zusammensetzung nur schwer zu bestimmen ist. Grundsätzlich umfaßte er all diejenigen, deren Besitz- und Lebensverhältnisse nicht genügten, um ihren Unterhalt ausreichend und dauerhaft zu sichern ${ }^{171}$. Dazu zähiten Kleinbauern mit nur wenig Eigenland, Pächter mit geringen Anbauflächen und Landlose. Sie alle lebten nicht oder nicht allein von landwirtschaftlicher Tätigkeit, sondern waren auf nebenerwerbliche Zuverdienste angewiesen. Zur Gruppe der Unterschichten sind ebenfalls zünftische Handwerker zu zählen, deren Existenz nicht oder nicht mehr durch das Prinzip der gerechten Nahrung gesichert war ${ }^{172}$, sowie Arme, Kranke, Bettler und Vaganten. Quantitativ läßt sich der Anteil der Unterschichten an der Gesamtbevölkerung nicht beziffern. Die Zahl derer, die zu den Unterschichten gehörten, war vor allem in den landwirtschaftlich wenig ertragreichen Gebieten wie der preußischen Grafschaft Tecklenburg beträchtlich. Dort rekrutierten sich die Unterschichten vornehmlich aus dem Kreis der unterbäuerlichen Schichten, die durch »Hollandgängerei « und anderweitige nebenerwerbliche Tätigkeiten in und außerhalb der Landwirtschaft ihren Lebensunterhalt sicherstellten ${ }^{173}$. Immer stärker schwollen die Unterschichten auch in jenen Gegenden an, die

winn- und Erwerbssteuer. Die Niederlassung war allerdings an den Nachweis eines Mindestvermögens geknüpft. Ebenso durften die im Herzogtum Berg ansässigen jüdischen Familien die Zahl von 215 nicht übersteigen - eine Vorschrift, die mehr Fiktion denn Realität war. Da die Familienväter drei Patente an Familienmitglieder vergeben konnten, überstieg die tatsächliche Anzahl der Familien die normative Vorgabe um ein Vielfaches. Siehe Scortr, Nr.2150; Rapport sur l'etat des Juifs du grand Duché de Berg [sic] des Verwaltungsrats Theodor Joseph Lenzen an Finanzminister Agar (1807/1808), HStAD, GB, Nr.171; LAU, Geschichte, S.181; RoB, Regierungsakten des Großherzogtums Berg, S. 33.

170 Bericht des Amtmannes der Ämter Broich und Styrum an Provinzialrat Spee vom 11. August 1807, HStAD, GB, Nr. 12473; RoB, Regierungsakten des Großherzogtums Berg, S.33.

171 Zur Begriffsdefinition vgl. Jürgen KockA, Weder Stand noch Klasse. Unterschichten um 1800, Bonn 1990, S.111; Josef MoosER, Ländliche Klassengesellschaft 1770-1848. Bauern und Unterschichten, Landwirtschaft und Gewerbe im östlichen Westfalen, Göttingen 1984, S.23; Arno Herzig, Unterschichtenprotest in Deutschland 1790-1870, Göttingen 1988, S. 5; GaLL, Gesellschaft, S. 8.

172 Das war beispielsweise im Wuppertal und in Duisburg der Fall. Siehe ENGELBRECHT, Herzogtum, S. 273f.; LERCH, Neuzeit, S. 173f.; zur Heterogenität der Gruppe der Handwerker allgemein: LENGER, Sozialgeschichte, S.18f.

173 Siehe ReEkERS, Beiträge, Teil 3: Tecklenburg-Lingen, Reckenberg, Rietberg und Rheda, in: Westfälische Forschungen 19 (1966) S.27-78, hier S.37; Hunsche, Landkreis, S. 40. 
über eine hohe gewerbliche Dichte verfügten, allen voran in den Gewerbegebieten des Herzogtums Berg.

Während das ständisch-korporative Ordnungsgefüge grundsätzlich noch überall Geltung hatte, waren an seinem Fundament deutliche Risse erkennbar. Durch die Bemühungen der Krone, eine leistungsorientierte und eigenen Normen verpflichtete Amtsträgerschaft aufzubauen, war zum einen die Privilegierung des Adels im politisch-administrativen Bereich weitgehend aufgeweicht ${ }^{174}$. Vor die Alternative gestellt, ihre Vorrechte bei der Besetzung von Verwaltungsstellen zu verlieren oder aber sich den veränderten Bedingungen im Amt zu beugen, war der Ritterschaft schon allein aus materieller Sicht keine andere Wahl geblieben, als umzudenken und sich den veränderten Einstellungsbedingungen anzupassen ${ }^{175}$. Die berufliche Qualifikation hatte somit schrittweise das Kriterium der Herkunft verdrängt. Ständische Norm und soziale Realität waren auseinandergetreten. Dieser Prozeß wurde durch Säkularisation und Mediatisierung beschleunigt, denn dadurch gingen dem Adel wichtige Versorgungsstellen verloren ${ }^{176}$. Insbesondere kamen ihm seine geistlichen Pfründen abhanden ${ }^{177}$. Die Aufweichung des ständischen Prinzips in der Verwaltung änderte summa summarum allerdings nichts an der gesellschaftlichen Vorrangstellung des Adels. Zwar war dieser als politische Führungselite entmachtet. Doch konnte er seine Privilegien als Geburtsstand retten. Er blieb steuerlich exemt, behielt einen eigenen Gerichtsstand und wahrte überdies seine grundherrliche Sonderstellung.

$\mathrm{Zu}$ Auflösungserscheinungen innerhalb der ständisch-korporativen Wirtschafts- und Gesellschaftsordnung führte ebenfalls der Gewerbeaufschwung ${ }^{178}$. Hiervon wurden einzelne der an Murat gefallenen Territorien im Verlauf des

174 Siehe allgemein Fehrenbach, Adel.

175 Zum Übergang zur berufsständischen Ordnung vgl. Lothar GALL, Vom Stand zur Klasse. Zu Entstehung und Struktur der modernen Gesellschaft, in: HZ 261 (1995) S.1-21, hier S.5f.; Hans JAEGER, Geschichte der Wirtschaftsordnung in Deutschland, Frankfurt a.M. 1988, S. 19.

176 Vgl. Dickmann, Stellung, S.24; Lahrkamp, Münster, S. 547.

177 Von bedeutendem Ausmaß war der Fortfall der Kirchenämter für den bergischen Adel, der durch seine ungünstige wirtschaftliche Lage von diesen besonders abhängig war. Ein Grund dafür war die geringe Eigenbewirtschaftung, die der bergische Adel betrieb. Da die Renteneinkünfte, die er von seinen Pächtern erhielt, nicht oder immer weniger ausreichten, um seinen Lebensstandard und die standesgemäße Versorgung seiner Nachkommen zu sichern, war er vor allem auf Kirchenämter angewiesen. Während ein Teil des Adels auf den Verlust der geistlichen Versorgungsstellen unflexibel reagierte und beharrlich auf seine hergebrachten Rechte pochte, zeigten einzelne Adelige einen gewissen Grad an Anpassungsbereitschaft, sei es, indem sie den Schulterschluß mit der Verwaltung vollzogen und innerhalb der landesherrlichen Verwaltung Karriere machten, oder aber, indem sie in ihrer Eigenschaft als Grundherren zu kapitalistischen Wirtschaftsformen übergingen und sich als Agrarunternehmer betätigten. Zum bergischen Adel siehe vor allem ENGELBRECHT, Herzogtum, S. 124f.; ferner WITTMÜTZ, Duché, S.175f.

178 Unter »Gewerbe « wird in diesem Zusammenhang in Anlehnung an Wolfgang voN STromer, Gewerbereviere und Protoindustrien in Spätmittelalter und Frühneuzeit, in: 
18. Jahrhunderts erfaßt, und zwar das Herzogtum Berg ${ }^{179}$, die preußischen Grafschaften Mark und Tecklenburg, die nassau-oranischen Fürstentümer Siegen und Dillenburg sowie die kleineren Anrainerprovinzen der Mark und des Herzogtums Berg: Gimborn-Neustadt, Homburg und Limburg. Der wirtschaftliche Aufschwung vollzog sich in diesen Gebieten nämlich außerhalb der bestehenden korporativen Ordnung mit ihren Zugangsbegrenzungen und Handlungszwängen. Neue Produktionszweige entstanden dort, wo sie nicht durch die alte Zunftverfassung behindert wurden, vor allem auf dem Land ${ }^{180}$. Das erleichterte die Produktion und erhöhte zugleich die Absatzmöglichkeiten. Dabei hatte sich neues Gewerbe auch deshalb im ländlichen Bereich angesiedelt, weil dort ein schnell anzulernendes und billiges Arbeitskräftepotential zur Verfügung stand. Verantwortlich dafür war zunächst, daß die im Vergleich zu den städtischen Verhältnissen geringen Löhne und Lebenshaltungskosten auf dem Land die Produktionskosten senkten, dann aber auch, $\mathrm{da} B$ in der Landbevölkerung ein hoher Bedarf an gewerblicher Tätigkeit bestand, weil sich viele bäuerliche Familien nur noch unzureichend von der Landwirtschaft $\mathrm{zu}$ ernähren vermochten ${ }^{181}$. Gerade dort, wo der landwirtschaftliche Anbau wegen der starken Parzellierung der bäuerlichen Besitzstellen oder aber aufgrund schlechter Bodenverhältnisse nur geringen Ertrag brachte, war man auf den Zugewinn aus gewerblicher Tätigkeit angewiesen ${ }^{182}$. Förderlich war für solche Familien, daß ihre Dienstverpflichtungen gegenüber den Grundherren nicht so umfangreich und zeitintensiv waren wie im Bereich der Gutsherrschaft ${ }^{183}$.

PoHL, Gewerbe- und Industrielandschaften, S.39-111, Zitat S.41, meine nachhaltige, marktbezogene Güterproduktion « verstanden.

179 Bei seiner Reise durch Westfalen im Jahre 1802 stellte GrUNER, „Wallfahrt«, S.137, fest, das Herzogtum Berg zähle »in Hinsicht seiner beispiellosen Industrie vielleicht zu den interessantesten in ganz Europa«. Zwar sei die Landwirtschaft noch mancher Verbesserung fähig, aber es sehe so aus, als richte sich »der Fleiß und die Industrie der Einwohner mehr auf Manufakturen und Fabriken-Arbeiten «.

180 Auch diese neuen Gewerbezweige wurden vor vermeintlicher Konkurrenz geschützt. Nur waren es nicht Zunftordnungen, sondern landesherrliche Privilegien und Monopole, die den Wettbewerb im Inland unterbanden. Vgl. ENGELBRECHT, Herzogtum, S.268f.; Max Braubach, Vom Westfälischen Frieden bis zum Wiener Kongreß (1648-1815), in: Franz Petri, Georg Droege (Hg.), Rheinische Geschichte, Bd.2: Neuzeit, Düsseldorf 1976, S.227-365, hier S.312.

181 KAUFHOLD, Gewerbelandschaften, S. 200f.

182 Zur Bedeutung, die das Gewerbe für die ländliche Bevölkerung in den einzelnen Territorien hatte, vgl. Lange, Gewerbe, S.76, 84f.; Stefan Gorissen, Georg WaGner, Protoindustrialisierung in Berg und Mark? Ein interregionaler Vergleich am Beispiel des neuzeitlichen Eisengewerbes, in: ZBGV 92 (1986) S. 163-171, hier S. 165f.; Hunsche, Landkreis, S.40f.; ReEkERS, Beiträge, Teil 3, S.33f.; Eckhardt BoLENZ, Johann Gottfried Brügelmann. Ein rheinischer Unternehmer zu Beginn der Industrialisierung und seine bürgerliche Lebenswelt, Köln 1993, S.34f.; SALER, Lage, S.6; DösSELER, Wirtschaft, S.71, 81.

183 KaUfHold, Gewerbelandschaften, S.188f. 
Die vorherrschende Organisationsform des ländlichen Gewerbes stellte das Verlagssystem dar ${ }^{184}$. Dieses war im Gegensatz zur zünftischen Produktion primär auf die Außenmärkte bezogen und am Gewinn orientiert ${ }^{185}$. Herstellung, Rohstoffbeschaffung und Warenverkauf erfolgten im Verlag getrennt voneinander. Die Lieferung der Rohstoffe und den Absatz der Waren besorgte ein kapitalkräftiger Kaufmann, der Verleger, während sich die von ihm Beschäftigten allein um die Anfertigung der Waren kümmerten. Die Produktion erfolgte überwiegend de- oder teilzentral. Oftmals zahlte der Verleger einen festen Lohn. Die Produzenten befanden sich in diesem Fall in einem reinen Erwerbsverhältnis. Das brachte ihnen den Vorteil, daß der Verleger Risiko und Kapitalbeschaffung allein trug, führte aber gleichzeitig dazu, daß die Beschäftigten keinen den Zunftmitgliedern vergleichbaren gewerblichen Schutz genossen und für Konjunkturschwankungen extrem anfällig waren. Wenn der Verleger bei rückläufigen Absatzmöglichkeiten die Produktion drosselte oder ganz einstellte, war der Unterhalt der Gewerbetreibenden nicht mehr gesichert.

Der gewerbliche Aufschwung wurde in vielen Territorien dadurch entscheidend mitbegünstigt, daß viele Landesfürsten keine prononciert merkantilistische Wirtschaftspolitik verfolgten und demzufolge relativ liberale wirtschaftspolitische Verhältnisse herrschten. Ganz besonders galt dies für das Herzogtum Berg, das wirtschaftspolitisch nicht zu den wittelsbachischen Kernlanden zählte und in dem die bayerische Regierung beinahe vollständig auf die Steuerung des ökonomischen Lebens verzichtete ${ }^{186}$. Dabei handelte es sich keineswegs um eine intentional betriebene liberale Gewerbepolitik. Die Zurückhaltung der bayerischen Regierung in Wirtschaftsfragen war vielmehr darauf zurückzuführen, daß man in München mit den Verhältnissen vor Ort nur mangelhaft vertraut war und auch nur wenig Interesse für die ökonomischen Belange des Herzogtums aufbrachte.

Dem fehlenden Engagement der Münchner Regierung im Gewerbesektor zufolge besaßen die Verwaltungsbehörden, die sich um die wirtschaftlichen

184 Zum Verlag siehe u.a.: Fernand BraUdEL, Sozialgeschichte des 15.-18. Jahrhunderts. Aufbruch zur Weltwirtschaft, Darmstadt 1990, S.663; Karl Heinrich KaufHoLd, Das Metallgewerbe der Grafschaft Mark im 18. und frühen 19. Jahrhundert, Göttingen 1976, S. 43; Lange, Gewerbe, S.92f.; Engelbrecht, Herzogtum, S.271f.; Braubach, Vom Westfälischen Frieden, S.313; WEHLER, Wirtschaftlicher Wandel, S.106.

185 Daneben war mancherorts das Kaufsystem vorbereitet. Im Unterschied zum Lohnsystem waren die Produzenten hierbei nach wie vor selbständig und erledigten alle Arbeitsvorgänge von der Besorgung des Materials bis hin zur Herstellung allein. Nur um den eigentlichen Absatz kümmerten sich Kaufleute, die die Waren zu einem bestimmten Preis abnahmen. Vgl. KaufHOLD, Metallgewerbe, S. 43; LANGE, Gewerbe, S. 92.

186 Das war nicht immer so gewesen. Vor der Jahrhundertwende hatte die bayerische Regierung das wirtschaftliche Leben im Herzogtum Berg weitaus stärker gelenkt und beispielsweise Privilegien für neue Gewerbezweige vergeben. Zur Entwicklung des bergischen Gewerbes vgl. ausführlich EnGELBRECHT, Herzogtum, S. 99f., 245f.; Jürgen Reulecke, Bergische Wirtschaft um 1800: Das Bergische Land an der Schwelle zur »Moderne«, in: Dreher, Engelbrecht, Das Herzogtum Berg, S. 23-26; ferner Bolenz, Brügelmann, S. 25. 
Angelegenheiten des Herzogtums kümmerten, auch nur einen geringen Organisations- und Differenzierungsgrad. Eine eigene mit Wirtschaftsfragen beauftragte Oberbehörde, wie es sie in anderen Gebieten bereits gab, existierte nicht. Die Zuständigkeit für Wirtschaftsangelegenheiten lag vielmehr in der Hand der Hofkammer. In den unteren Behörden war die Aufgabenverteilung noch undurchsichtiger, weil neben den lokalen Verwaltungsorganen die Zünfte wesentliche Funktionen im ökonomischen Bereich erfüllten.

Der preußische König beanspruchte in seinen Außenprovinzen deutlich mehr Lenkungsanspruch auf die wirtschaftlichen Verhältnisse als der bayerische Landesherr am Niederrhein ${ }^{187}$. In der Grafschaft Mark etwa förderte bzw. reglementierte er das Gewerbe in weitaus höherem Maße als dies in Düsseldorf der Fall war. Zudem grenzte er die Grafschaft im Rahmen seiner auf die Förderung der Mittel- und Ostprovinzen ausgerichteten Wirtschaftspolitik handelspolitisch aus dem Königreich aus. Sie war für Preußen in wirtschaftlicher Hinsicht Ausland und durfte das Gros ihrer Erzeugnisse nicht in die geschützten Gebiete ausführen ${ }^{188}$ - hierin bestand in der Tat eine Parallele zum Herzogtum Berg. Allerdings erfolgte auch der preußische Zugriff auf das märkische Gewerbe - und das galt im übrigen für alle anderen, dem Königreich integrierten westfälisch-niederrheinischen Territorien - nicht systematisch und einheitlich ${ }^{189}$. Die Steuerungsversuche der Regierung waren in erster Linie gesonderte Maßnahmen für bestimmte Gewerbezweige, Branchen, Personengruppen, Gegenden oder gar einzelne Orte der gewerbeintensiven Zonen im Süden des Landes ${ }^{190}$. Zudem handelte es sich um ad hoc ge-

187 Zur preuBischen Wirtschaftspolitik in der Mark siehe KAUFHOLD, Metallgewerbe, S.68f.; LaNGE, Gewerbe, S.77f.

188 Handelserleichterungen bestanden in beschränktem Maße für einzelne Warenexporte. Siehe Gorissen, Steuerreform, S.196f.; Reininghaus, Wirkung, S.164f.; KaufHold, Metallgewerbe, S. 38f.

189 Flächendeckenden Charakter besaßen die Bestrebungen der Regierung, das Landhandwerk der Grafschaft in Anlehnung an die kurmärkischen Zustände in die Städte zu verbannen. Vgl. LANGE, Gewerbe, S. 81f.; Wilfried ReiningHaus, Zünfte, Städte und Staat in der Grafschaft Mark. Einleitung und Regesten von Texten des 14. bis 19. Jahrhunderts, Münster 1989, S.32f.

190 Das zeigte sich beispielsweise an der Schaffung einer für das Eisen- und Metallgewerbe verantwortlichen Fabrikenkommission und an den Einzelverfügungen, mit denen die preußische Regierung einzelne Gewerbezweige gesondert standardisierte. So besaß die Draht- und Halbzeugproduktion des Süderlandes ein eigenes Regelwerk, das die dortigen Lohn-, Absatz- und Preisverhältnisse festen Normen unterwarf. Durch Stapel und Kartelle wurde der Absatz geregelt. Darüber hinaus verteilte sich die Drahtherstellung der Mark auf die Orte Altena, Lüdenscheid und Iserlohn. Lüdenscheid stellte groben Draht her, Altena Mitteldraht und Iserlohn feinen Draht. Flankiert wurde die süderländische Ordnung durch die Einrichtung sogenannter Fabriken, die, korporativ verfaßt, sämtlichen $B e-$ schäftigten einer Branche gewerblichen Schutz boten, sie aber zugleich staatlicher Aufsicht unterstellten. An den zünftisch stärker geprägten Orten, vor allem den älteren märkischen Hauptstädten, tolerierte die Regierung dagegen den Fortbestand der Zünfte, griff allerdings in deren Statuten und Mitspracherechte ein. Daneben versuchte sie, auswärtige Gewerbetreibende durch Befreiungen von der Steuerleistung und prohibitive Zöl- 
fällte Entscheidungen, die auf konkrete Probleme und Notlagen eine Antwort gaben, nicht aber auf festen Zielvorstellungen beruhten. Oftmals hatte das märkische Gewerbe sogar selbst um Interventionen nachgesucht ${ }^{191}$. Von einer planvollen und konsequent betriebenen Gewerbepolitik konnte deshalb selbst in der Grafschaft Mark nicht die Rede sein. Ohnehin ließ sich die Wirtschaft ungleich schwerer von oben steuern als etwa die Verwaltung. Dies zeigte sich einmal daran, daß die Eingriffe der Regierung dem Gewerbe zuweilen mehr schadeten, als sie ihm dienten. Beispielsweise führten die festen Abnahmebedingungen im Metallgewerbe zu Überproduktion und Qualitätseinbußen statt zur geplanten Begrenzung der hergestellten Warenmenge und zur Gütesicherung ${ }^{192}$. Es ließ sich auch daran erkennen, daß die landesherrlichen Reglementierungsversuche Handel und Gewerbe minunter nicht beabsichtigte Vorteile brachten. So führten die Bemühungen der Regierung, Stadt und Land gewerblich zu trennen, nicht, wie ursprünglich geplant, zur eingeschränkten Niederlassung des Handwerks auf dem Land, sondern letztendlich zum Gegenteil. Sie bewirkten die Liberalisierung der Gewerbeverfassung. Das platte Land erhielt für den bestimmten jährlichen Betrag auf immer die völlige Consumtions-, Handlungs- und Gewerbe-Freyheit, ohne städtischen Accise- und Gilde-Zwang oder Gilde-Beitrag ${ }^{193}$. Damit stellte die Grafschaft Mark unter den Provinzen des Großherzogtums einen einzigartigen Fall dar, denn selbst im Herzogtum Berg bestand trotz der liberalen Ansätze in der Wirtschaftsverfassung keine Gewerbefreiheit. Als fruchtbar für die gewerbliche Entwicklung in der Mark erwies sich ebenfalls die Ausklammerung der Grafschaft aus dem preußischen Außenhandelssystem. Sie begünstigte die ohnehin ausgeprägte Exportorientiertheit des märkischen Gewerbes und federte dadurch die Hemmnisse, die der Ausschluß von den Märkten der Kernlande verursachte, stark ab ${ }^{194}$. Die wirtschaftliche Entwicklung der Grafschaft Mark verlief somit weitgehend unabhängig von den preußischen Kernlanden ${ }^{195}$.

Für die bestehende Wirtschafts- und Sozialordnung besaß die Ausdehnung des Gewerbes auf den ländlichen Bereich in dreifacher Weise Rück-

le anzulocken. Mehr noch als die Eisen- und Metallverarbeitung im Süderland wurde der märkische Bergbau dem landesherrlichen Verwaltungsapparat eingegliedert. Für Einstellung, Entlassung und Bezahlung der Bergarbeiter war das eigens dafür eingerichtete märkische Bergamt zuständig, dem auf Initiative des Freiherrn vom Stein im Jahre 1792 ein Oberbergamt als Oberbehörde angegliedert wurde. Im übrigen war die Bevölkerung der gewerbeintensiven Distrikte südlich der Ruhr vom Dienst an der Waffe befreit. Zu den preußischen Wirtschaftsmaßnahmen in der Mark vgl. Köllmann, Freiherr vom Stein, S.24f.; KaufHold, Metallgewerbe, S. 18f.; ReininghauS, Zünfte, S.30f.; Lange, Gewerbe, S.79, 81f.; Brand, Geschichte, S. 14; KLoosterhuis, Fürsten, S.152f.

191 KaufHold, Metallgewerbe, S.70; Reininghaus, Zünfte, S. 31.

192 KAUfHOLd, Metallgewerbe, S. 20, 25f.

193 Zit. nach ReInINGHAUs, Zünfte, S.36. Vgl. auch GoRISSEN, Steuerreform, S.208f.

194 KaUfHold, Metallgewerbe, S. 69.

195 KöllmanN, Freiherr vom Stein, S. 24. 
kopplungseffekte ${ }^{196}$. Die gewerbliche Erschließung eines primär von landwirtschaftlicher Tätigkeit geprägten Raumes führte erstens dazu, daß sich der agrarische Charakter der Gesellschaft beträchtlich verwässerte. In den bergischen Gewerbelandschaften war die agrarische Sozialordnung durch die Abhängigkeit der Einwohner von der Tätigkeit im Gewerbe sogar weitgehend in eine gewerbliche überführt worden. Durch die wirtschaftliche Entfaltung auf dem Land wurden zweitens die Zünfte in erhebliche Existenzund Legitimationsnöte gebracht. Die Niederlassung unzünftischen Gewerbes auf dem Land führte nämlich nicht nur dazu, daß die der Zunftverfassung immanente wirtschaftliche Trennung zwischen Stadt und Land verlorenging. Mit seinen gewinnmaximierenden Produktionsformen untergrub das außerzünftische Gewerbe zusätzlich in wachsendem Maße das Prinzip der gerechten Nahrung, auf dem die gesamte korporative Ordnung beruhte und das die Einkommensbasis der zünftisch gebundenen Handwerker sicherstellte. Die korporativ verfaßten Handwerker blieben zwar noch in die ständische Sozialordnung eingebunden. Ihre Subsistenz geriet aber zusehends in Gefahr. Die Zünfte waren in der Regel nicht flexibel genug, um mit den gewerblichen Entwicklungen Schritt zu halten ${ }^{197}$. Ihre Anzahl ging drastisch zurück. Darüber hinaus brachen an verschiedenen Orten schwere Zunftunruhen aus ${ }^{198}$. Eng mit der Erosion der korporativen Wirtschaftsverfassung zusammenhängend, verursachten die ökonomischen Wandlungsprozesse drittens soziale Umschichtungen am Rand der altständischen Gesellschaft, wobei es sich im Keim um Ansätze zur Klassenbildung handelte ${ }^{199}$. Zum einen stieg die Zahl der in ihrem Unterhalt gefährdeten Einwohner gerade in jenen Gegenden, die über eine hohe gewerbliche Dichte verfügten, allen voran in den Gewerbegebieten des Herzogtums Berg ${ }^{200}$, im 18. Jahrhundert

196 Einige Historiker sehen im ländlichen Gewerbe eine Vorform der industriellen Produktion und haben dafür das Modell der Proto-Industrialisierung entwickelt. Das Modell ist bis heute umstritten. Vgl. Peter KriedtKe u. a., Sozialgeschichte in der Erweiterung Proto-Industrialisierung in der Verengung? Demographie, Sozialstruktur, moderne Hausindustrie: eine Zwischenbilanz der Proto-Industrialisierungs-Forschung (Teil I), in: Geschichte und Gesellschaft 18 (1992) S.71-87, hier S.76, 84f.; demgegenüber STromER, Gewerbereviere; GoRISSEN, WAGNER, Protoindustrialisierung.

197 Beispielsweise konnten die Lenneper Zünfte ihre Produktion auf feine Tuche umstellen, aufgrund bestehender Zunftzwänge ihre Produktion jedoch nicht steigern. Wilhelm GebHard (Hg.), Bericht des Hof-Kammerrats Friedrich Heinrich Jacobi über die Industrie der Herzogtümer Jülich und Berg aus den Jahren 1773 und 1774, in: ZBGV 18 (1882) S.1-148, hier S.51; vgl. Burkhard DieTZ, Im Zeichen des Mittelalters: Aufstieg und Niedergang des Tuchgewerbes in Wipperfürth 1462-1803, in: ZBGV 90 (1982/1983) S.46-83. 198 Müller, Herrschaft, S.181; LahrKamp, Münster, S.502; Engelarecht, Herzogtum, S.271f.

199 Vgl. zum Klassenbildungsprozeß allgemein Christof DIPPER, Übergangsgesellschaft. Die ländliche Sozialordnung in Mitteleuropa um 1800, in: ZHF 23 (1996) 1, S. 57-87, hier S.67.

200 So beispielsweise in Elberfeld und Barmen. Vgl. Eberhard ILLNER, Bürgerliche Organisierung in Elberfeld 1775-1850, Neustadt a.d. Aisch 1982, S.24; Wolfgang KöllmanN, Sozialgeschichte der Stadt Barmen im 19. Jahrhundert, Tübingen 1960, S.5, 131f.; ENGEL- 
stark an, weil immer mehr Einwohner in den Sog des Marktgeschehens gerieten $^{201}$. Forcierend wirkten hierbei die Bevölkerungsexplosion und Hungerkrisen. Zum anderen kam es zur Genese einer neuen gesellschaftlichen Gruppe: der Unternehmer und Kaufleute ${ }^{202}$. Da sich diese im Rahmen des gewerblichen Aufschwungs formiert hatte, waren es in erster Linie wirtschaftliche Kriterien wie Gewinnmaximierung und Marktbezogenheit, die ihre Existenz determinierten. In einem Punkt bestand aber eine Parallele zum altständischen Stadtbürgertum. Auch die Kaufmannschaft verfügte nicht selten über Grundeigentum ${ }^{203}$.

Ökonomisch konnten Unternehmer und Kaufleute die alten Eliten im 18. Jahrhundert oftmals überflügeln. Im politischen Bereich hingegen vermochten sie diese kaum zu verdrängen. Nur im kommunalen Bereich gelang es ihnen mitunter, ihre wirtschaftliche Bedeutung dauerhaft in eine politische und soziale Führungsposition umzuwandeln ${ }^{204}$. Ermöglicht wurde dieser Sprung in die lokale Honoratiorenschaft nicht zuletzt durch die Knüpfung verwandtschaftlicher Beziehungen mit alteingesessenen Bürgerfamilien. Höheren Orts blieben der Kaufmannschaft politische Partizipationsmöglichkeiten in der Regel jedoch versagt. Das galt selbst für das ehemalige Herzogtum Berg, wo sich bei Eingliederung der linksrheinischen Gebiete in das französische Empire Anzeichen dafür mehrten, daß die führenden wirtschaftlichen Kräfte ihre Machtlosigkeit im Bereich der Landespolitik nicht länger akzeptierten $^{205}$. Durch den Verlust des linken Rheinufers wurde das rechtsrheinische Gewerbe nicht nur von lebenswichtigen Absatzmärkten abgeschnitten ${ }^{206}$, sondern grundsätzlich aus einem Wirtschaftsraum herausgelöst, zu dem es bis

BRECHT, Herzogtum, S. 273f.; GrUNER, "Wallfahrt«, S.135f.; Angelika RiEMANN, Krieg, Verelendung und Armenpolitik, in: Dreher, Engelbrecht, Das Herzogtum Berg, S.61-70, hier S.61f.

201 Dagegen gab es nach KaUfHOLD, Metallgewerbe, S. 67f., in der Grafschaft Mark keine völlig verarmte Unterschicht.

202 Vgl. Engelbrecht, Herzogtum, S.163f.

203 Vgl. Max BarkHauSEN, Staatliche Wirtschaftslenkung und freies Unternehmertum im westdeutschen und im nord- und südniederländischen Raum bei der Entstehung der neuzeitlichen Industrie im 18. Jahrhundert, in: VSWG 45 (1958) S. 168-241, hier S. 236; KAuFHOLD, Metallgewerbe, S. 58f.

204 Beispielsweise gelang es der lokalen Kaufmannschaft in Elberfeld, in das Stadtregiment aufzusteigen. Vgl. ENGELBRECHT, Herzogtum, S.171f.; KöllmaNN, Sozialgeschichte, S. 10 .

${ }^{205}$ In der Krisensituation am Ausgang des 18. Jahrhunderts war es den führenden bergischen Gewerbetreibenden nur gelungen, an der Repartition der Kontribution beteiligt zu werden. Vgl. EnGElbrecht, Herzogtum, S. 249.

206 Über den Zustand des Elberfelder Gewerbes schrieb der preußische Kriegs- und Domänenrat Christian F. Meyer während einer Dienstreise im Jahre 1794, die Fabriken seien bei gegenwärtigen kriegerischen Zeiten - zumal, da nach Frankfurt kein Warenabzug erfolgen kann, und Rhein und Maas gesperrt sind - in ganz elender Verfassung, und es [sei] nicht die halbe Arbeit gegen vorige Zeiten vorhanden. Zit. nach Christian F. MEYER, Ein Kriegsrat auf Dienstreise, hg. von Günther Elbin, Duisburg 1986, S. 70. 
dahin in vielfacher Hinsicht gehört hatte ${ }^{207}$. Einige Kaufleute, deren Produktion nicht standortgebunden war, verlagerten ihr Gewerbe daraufhin auf das linke Rheinufer oder richteten dort Zweigstellen ein, ohne daß die bayerische Regierung diese Abwanderung von Kapital und Arbeitskräften einzudämmen wußte ${ }^{208}$. Gleichzeitig schlossen sich führende Gewerbetreibende an mehreren Orten des Herzogtums erstmals zu branchenübergreifenden Vertretungsorganen zusammen und versuchten aktiv auf die bayerische Wirtschaftspolitik in Berg Einfluß zu nehmen ${ }^{209}$. Sie verlangten von der Münchner Regierung, dem durch die Verschiebung der französischen Zollinie an den Rhein ${ }^{210}$ geschwächten bergischen Gewerbe mehr Beistand zu leisten als bisher. Dazu gehörten ihrer Meinung nach der Abschluß von Außenhandelsverträgen - angesichts der veränderten außenwirtschaftlichen Konstellationen für das bergische Gewerbe gleichsam eine Überlebensfrage - sowie die Schaffung neuer Institutionen zum rechtlichen Schutz und zur wirtschaftlichen Unterstützung des Gewerbes. Konkret drangen sie auf die Bildung von Handelskammern und Gewerbegerichten nach französischem Vorbild ${ }^{211}$. Die in den 1790er Jahren in Düsseldorf aufkommende bürgerliche Oppositionsbewegung reklamierte in Reaktion auf die enge Verzahnung zwischen städtischen und landesherrlichen Führungsschichten sowie auf die zerrütteten Finanzen der Stadt darüber hinaus Kontrollfunktionen gegenüber dem Magistrat und drang zunehmend auf institutionalisierte Partizipationsmöglichkeiten innerhalb der Stadtverwaltung 212. Obwohl die Kaufleute bei einigen Düsseldorfer Regierungsbeamten auf Resonanz und Unterstützung stießen, verliefen ihre Bemühungen summa summarum ohne Ergebnisse. Als sich die innenpolitische Situation nach 1800 langsam entspannte, ließ die Regierung die Reformvorschläge auf sich beruhen. Immerhin aber erkannte sie den in Düsseldorf zustande gekommenen Handlungsvorstand offiziell $\mathrm{an}^{213}$.

207 Engelbrecht, Herzogtum, S.26f.; Hermann Ringel, Bergische Wirtschaft zwischen 1790 und 1860. Probleme der Anpassung und Eingliederung einer frühindustriellen Landschaft, Neustadt a. d Aisch 1966, S. 108.

208 Vgl. ReUlecke, Wirtschaft, S. 25; Wilhelm ENGels, Maßnahmen der bergischen Regierung gegen die Abwanderung der hiesigen Industrie in der zweiten Hälfte des 18. und zu Anfang des 19. Jahrhunderts, in: ZGBV 64 (1936) S. 8-22, hier S.12f.

209 Einer der Hauptvertreter des bergischen Gewerbes war der Unternehmer Johann Gottfried Brügelmann, der in der Nähe Ratingens eine mechanische Baumwollspinnerei betrieb. Zur Figur Brügelmanns siehe Bolenz, Brügelmann, passim; Jörg ENGELbRECHT, Die Familie Brügelmann als »Agrarunternehmer « im Raum Ratingen, in: Ratinger Forum 2 (1991) S. 56-75; ferner DERS., Herzogtum, S. 109f., $179 f$.

210 Ringel, Wirtschaft, S. 108.

211 Mit der Orientierung am französischen Modell signalisierte die Kaufmannschaft eindeutig, daß sie sich in gewerblicher Hinsicht dem linken Rheinufer und nicht den bayerischen Hauptlanden verbunden fühlte, wenn sie auch die politische Zugehörigkeit des Herzogtums zum Hause Wittelsbach nicht in Frage stellte.

212 Vgl. Mémoire et Extrait d'un livre déjà présenté au Roi de Bavière concernant l'organisation du Magistrat de Dusseldorf (1805), HStAD, GB, Nr.4425; ferner Müller, Herrschaft, S.108f.

213 Engelbrecht, Herzogtum, S.245f. 


\subsection{Gewerbelandschaften}

Der Gewerbeaufschwung, der verschiedene Territorien des Großherzogtums im 18. Jahrhundert erfaßte, war ein regionales, mitunter lokales Phänomen. Ausprägung und Dichte des Gewerbes innerhalb der Provinzen waren deshalb äußerst unterschiedlich. Einerseits gab es Räume, in denen der Anteil des Gewerbes an der Erwerbstätigkeit von geringer Bedeutung war, wie das vormalige Erbfürstentum Münster ${ }^{214}$ und die Grafschaft Dortmund ${ }^{215}$. Diesen traditional geprägten Gebieten standen andererseits ökonomisch fortgeschrittene Gewerbelandschaften mit hoher gewerblicher Tätigkeit gegenüber, in denen die Landwirtschaft zuweilen ihre Vorrangstellung als Erwerbsquelle ganz und gar verloren hatte. Solche Gebiete mit hoher gewerblicher Aktivität wiesen drei Gemeinsamkeiten auf. Zum ersten hatten sie ähnliche Gewerbezweige ausgebildet. Zum zweiten produzierten sie vornehmlich für den Export - die Waren gingen namentlich nach Frankreich, Italien, Spanien, Portugal, Holland, Polen und Übersee ${ }^{216}$. Zum dritten standen sie durch intensive Austauschbeziehungen miteinander in enger Verbindung. Verflechtungen herrschten insbesondere bei der Rohstoffversorgung, weil sich produktionsintensive Gebiete in unmittelbarer Nachbarschaft zu rohstoffreichen Regionen entwickelt hatten ${ }^{217}$. Dies hatte schon früh zu regionaler Arbeitsteilung und zur Spaltung der Gewerbelandschaften in rohstofferzeugende und -verarbeitende geführt ${ }^{218}$.

Einer der wichtigsten Wirtschaftszweige war die Eisen- und Metallproduktion. Als Rohstofflieferant diente vor allem das Siegerland, das einen Teil des in den einzelnen Territorien notwendigen Eisens erzeugte. Metallverarbeitendes Gewerbe gab es dort nicht. Vom Siegerland aus gingen die Halbfabrikate zur Weiterverarbeitung in die Grafschaft Mark, das Herzogtum Berg sowie die Herrschaften Gimborn-Neustadt und Homburg ${ }^{219}$. Diese Territorien stellten Eisen zwar auch selbst her, konnten damit aber ihren Bedarf bei weitem

214 Die kurze preußische Herrschaftsphase hatte im gewerblichen Bereich nur geringe Spuren hinterlassen. Zur Gewerbestruktur im Erbfürstentum Münster vgl. REEKERS, Beiträge, Teil 1: Paderborn und Münster, in: Westfälische Forschungen 17 (1964) S. 83-176, hier S.116f.; ferner LaHRKamP, Münster, S. 483f.

215 Reekers, Beiträge, Teil 6: Grafschaft Limburg und Reichsstadt Dortmund, in: Westfälische Forschungen 23 (1971) S.75-106, hier S. 84f.; SснамвасH, Stadtbürgertum, S. 15f.

216 Tableau de l'Industrie du Grand Duché de Berg telle qu'elle étoit autrefois \& telle qu'elle est aprésent [sic] vom 12. April 1809, verfaßt von dem Elberfelder Kaufmann Gerhard Siebel, HStAD, GB, Nr.5592; RINGEL, Wirtschaft, S. 106f.; KAUFHold, Metallgewerbe, S.38f. 217 Charakteristisch für diese Gebiete war zudem, daß sie häufig von auswärtigen Lebensmittelzufuhren abhingen. Das galt namentlich für die Grafschaft Mark und das Herzogtum Berg. Vgl. ibid., S.40f., 67; Engelbrecht, Herzogtum, S.26f.; Gorissen, Wagner, Protoindustrialisierung, S.166.

$218 \mathrm{Vgl}$. KaUfHOLD, Gewerbelandschaften, S.182f.

219 Reekers, Beiträge, Teil 7, S.114f.; Kaufhold, Gewerbelandschaften, S.155f.; EngeLBRECHT, Herzogtum, S. 109; DöSSELER, Wirtschaft, S.58f. 
nicht decken ${ }^{220}$. Eisen- und metallverarbeitendes Gewerbe von Bedeutung befand sich darüber hinaus noch in der Grafschaft Limburg221. Regional war die Metallproduktion in den einzelnen Territorien äußerst ungleich verteilt. In der Grafschaft Mark ballte sich das Gewerbe in dem für landwirtschaftliche Zwecke kaum geeigneten, aufgrund seiner gebirgigen Lage für die gewerbliche Nutzung jedoch vorteilhaften Süderland ${ }^{222}$. Zwischen $20 \%$ und $25 \%$ der Bevölkerung waren hier im Metallgewerbe tätig, während in der gesamten Grafschaft der Beschäftigungsanteil im Metallgewerbe bei durchschnittlich $10 \% \mathrm{lag}^{223}$. Gleiches galt für die an die Mark angrenzende Grafschaft Limburg und das Herzogtum Berg. In Limburg beschränkte sich das Eisen- und Metallgewerbe auf den flußreichen Südteil des Landes ${ }^{224}$. Im wittelsbachischen Berg lag sein Schwerpunkt am Rande der steilen Hanglagen des bergischen Landes mit seinen leicht erschließbaren Energiequellen. Hauptstandorte waren Solingen und Remscheid 225 . Neben der Scheidung in Rohstofferzeugung und -verarbeitung erfolgte auch die Produktion vielfach bereits in interterritorialer Arbeitsteilung. Die Grafschaft Mark produzierte vornehmlich gröbere Eisenwaren - insbesondere wurde hier Draht gezogen ${ }^{226}$. Die Produktionsstätten des Herzogtums Berg beschäftigten sich dagegen hauptsächlich mit der Anfertigung von Kleineisenprodukten und Klingen.

Einen beachtlichen Platz innerhalb der Gewerbelandschaft nahm ebenfalls die Textilverarbeitung ein ${ }^{227}$. Sie war ähnlich hochspezialisiert und differen-

220 Ibid. S.55f.

221 Eisengewerbe wurde ferner in der Grafschaft Dortmund betrieben, war dort aber vergleichsweise unbedeutend. Etwa 5\% der Erwerbstätigen in Dortmund arbeiteten im Eisen- und Metallgewerbe. Vgl. Schambach, Stadtbürgertum, S.18; ReEKERS, Beiträge, Teil 6, S.91.

222 Zum Eisengewerbe in der Grafschaft Mark ausführlich: KaUfHOLD, Metallgewerbe; Ders., Gewerbelandschaften, S.158f.; ReEkERs, Beiträge, Teil 5: Grafschaft Mark, in: Westfälische Forschungen 21 (1968) S. 98-161, hier S.117; GoRIsSEN, WAGNER, Protoindustrialisierung.

223 KaUfHOLD, Metallgewerbe, S.10f.

224 Reekers, Beiträge, Teil 6, S. 79f.; KLueting, Ständewesen, S.119f.

225 Zum bergischen Eisen- und Metallgewerbe vgl. GoRISSEN, WAGNER, Protoindustrialisierung; KaUFHOLD, Gewerbelandschaften, S. 159f.; ENGELBRECHT, Herzogtum, S. 107f.; Alphons Thun, Die Industrie am Niederrhein und ihre Arbeiter, Zweiter Theil: Die Industrie des bergischen Landes (Solingen, Remscheid und Elberfeld-Barmen), Leipzig 1879, S. 7f.; Joachim Kermann, Die Manufakturen im Rheinland 1750-1833, Bonn 1972, hier S.160f., 532f.; BARKHAUSEN, Wirtschaftslenkung, S. 181f.

226 Einzig die Produktpalette der Grafschaft Limburg deckte sich weitgehend mit der der preußischen Mark.

227 Neben der Eisen-, Metall- und Textilverarbeitung gab es noch Seifensiedereien, Tabak- und Papierfabriken, Essig- und Bierbrauereien sowie Produktionsstätten zur Lederherstellung. Sie waren unter anderem im Herzogtum Berg, in Gimborn-Neustadt und in Homburg, im Siegerland, in der Grafschaft Mark sowie in Duisburg und Dortmund zu finden. Ansonsten kam dem Steinkohlebergbau noch Bedeutung zu. Die wichtigsten Abbaugebiete befanden sich in den preußischen Gebieten Mark, Essen, Werden und Tecklenburg. Vgl. Tableau de l'Industrie du Grand Duché de Berg telle qu'elle étoit autrefois 
ziert wie die Eisen- und Metallproduktion, hing aber in weitaus stärkerem Maße von der Zufuhr auswärtiger Rohstoffe ab. Vor allem Baumwolle, Wolle, Seide und Leinen mußten von auswärts bezogen werden. Zu wichtigen Rohstofflieferanten gehörten Spanien, Hessen, Schlesien sowie der norddeutsche Raum $^{228}$. Außerdem verfügte das Textilgewerbe über eine wesentlich breitere Streuung und flächenmäßige Dichte als die Metallproduktion, zum einen, weil es weniger standortgebunden war, zum anderen, weil es ohne spezielle handwerkliche Kenntnisse leicht im Heimgewerbe betrieben werden konnte. Von hoher Bedeutung war die Textilproduktion im Herzogtum Berg, und dort besonders in der Gegend um Elberfeld und Barmen, wo seit dem 16. Jahrhundert das kalkarme Wasser der Wupper für die Garnveredelung genutzt wur$\mathrm{de}^{229}$, sowie in Lennep und Hückeswagen. Während im Wuppertal vor allem Baumwolle, Leinen und Seide verarbeitet wurden ${ }^{230}$, konzentrierte sich das Lenneper und Hückeswagener Textilgewerbe auf die Anfertigung von Tuchen $^{231}$. Textilverarbeitung wurde im Herzogtum darüber hinaus in Mülheim am Rhein betrieben ${ }^{232}$. Einen zweiten regionalen Schwerpunkt besaß die Textilverarbeitung in der Grafschaft Mark südlich der Ruhr ${ }^{233}$. Um Schwelm, Hattingen, Hagen und Herdecke bestand ein ausgeprägtes Textilgewerbe, das neben Baumwolle auch Leinen, Samt und Seide verarbeitete. Beinahe die

\& telle qu'elle est aprésent [sic] vom 12. April 1809, verfaßt von dem Elberfelder Kaufmann Gerhard Siebel, HStAD, GB, Nr.5592; ferner Lenzen, Beyträge, Bd.1, S.18f.; Dösseler, Wirtschaft, S.68f.; REEKERS, Beiträge, Teil 3, S.38f., 134f.; DiES., Beiträge, Teil 7, S.127, 130; KaUfHOLD, Gewerbelandschaften, S. 156; LANGE, Gewerbe, S.66f.; LERCH, Neuzeit, S.169, 497f.; Braubach, Vom Westfälischen Frieden, S.317; Schambach, Stadtbürgertum, S. 18f.; Demian, Statistik, S. 64; Brand, Geschichte, S.14, Anm. 16; Hunsche, Landkreis, S. 41.

228 Siehe den Bericht des Hof-Kammerrats Friedrich Heinrich Jacobi; ferner KaUfHOLD, Gewerbelandschaften, S. 182; BarKHAuSEN, Wirtschaftslenkung, S. 183.

229 Zum Textilgewerbe im Wuppertal siehe Thun, Industrie, S. 163f.; Klaus GoEBeL, Zuwanderung zwischen Reformation und Franzosenzeit. Ein Beitrag zur vorindustriellen Bevölkerungs- und Wirtschaftsgeschichte Wuppertals 1527-1808, Wuppertal 1966, S.38f.; Jürgen Reulecke, Die industrielle Entfaltung des Wuppertals im 19. Jahrhundert, in: Horst Jordan, Heinz WolfF (Hg.), Werden und Wachsen der Wuppertaler Wirtschaft. Von der Garnnahrung 1527 zur modernen Industrie, Wuppertal 1977, S. 49-72, hier S.50f.; Braubach, Vom Westfälischen Frieden, S.317; BarkHausen, Wirtschaftslenkung, S.179f.

230 Tableau de l'Industrie du Grand Duché de Berg telle qu'elle étoit autrefois \& telle qu'elle est aprésent [sic] vom 12. April 1809, verfaßt von dem Elberfelder Kaufmann Gerhard Siebel, HStAD, GB, Nr.5592; KaUfHOLd, Gewerbelandschaften, S.161; Braubach, Vom Westfälischen Frieden, S.317.

231 KermanN, Manufakturen, S.160f.; KaUfHold, Gewerbelandschaften, S.163; BraUBACH, Vom Westfälischen Frieden, S.316.

232 Zugewanderte Protestanten aus Köln hatten hier ein florierendes Seiden- und Samtgewerbe aufgebaut. Siehe Clemens von Looz-Corswarem, Köln und Mülheim am Rhein im 18. Jahrhundert. Reichsstadt und Flecken als wirtschaftliche Rivalen, in: Helmut JäGER u. a. (Hg.), Civitatum Communitas. Studien zum europäischen Städtewesen. Festschrift für Heinz Stoob, Teil 2, Köln, Wien 1984, S. 543-564, hier S. 550f.; ferner KaUfHOLD, Gewerbelandschaften, S.163; BarKHausen, Wirtschaftslenkung, S.180; Braubach, Vom Westfälischen Frieden, S. 316.

233 Vgl. ReEKERS, Beiträge, Teil 5, S.128f. 
Hälfte aller märkischen Textilarbeiter war in diesem Raum tätig. Die höchste Konzentration wies hierbei das Hochgericht Schwelm auf ${ }^{234}$. Abgesehen von den bergischen und märkischen Textilverarbeitungszentren wurde in der im Klevischen gelegenen Stadt Duisburg ${ }^{235}$, in der Grafschaft Steinfurt, im Amt Deutz, in den nassau-oranischen Gebieten - in der Grafschaft Dortmund war mehr als ein Zehntel der gewerblich Beschäftigten in der Textilproduktion tätig 236 -, im Vest Recklinghausen, in der Herrschaft Rheda und in der Grafschaft Tecklenburg Textilverarbeitung betrieben. In Duisburg stellte man vor allem Tuche her ${ }^{237}$, in Deutz bestand eine Seiden- und Seilfabrikation ${ }^{238}$, im Vest Recklinghausen wie auch im Siegerland wurde Baumwolle gesponnen, ${ }^{239}$ in Dortmund, Steinfurt, Rheda und Tecklenburg herrschte die Leineweberei vor $^{240}$. Letztere stellte in Tecklenburg sogar den einzigen Produktionszweig dar. Beinahe vier Fünftel aller Beschäftigten waren, größtenteils nebengewerblich, in der Leinenherstellung tätig ${ }^{241}$.

234 Ibid. S. 128.

235 Duisburg stellte im rechtsrheinischen Teil des ehemaligen Herzogtums Kleve das wichtigste Gewerbegebiet dar, wie aus der Übersicht bei Gisela VolLMER, Eine Fabrikenstatistik des Herzogtums Kleve aus dem Ende des 18. Jahrhunderts, in: Düsseldorfer Jahrbuch 46 (1954) S. 182-203, besonders S. 193f., hervorgeht.

236 SснамвасH, Stadtbürgertum, S. 18.

237 Lerch, Neuzeit, S.166f.; KermanN, Manufakturen, S. 171f.; Barkhausen, Wirtschaftslenkung, S.229f.

238 Braubach, Vom Westfälischen Frieden, S. 319.

239 In Recklinghausen bestand darüber hinaus Tuchgewerbe, während im Siegerland zudem Leinen und Wolle verarbeitet wurden. BeTTE, Recklinghausen, S. 72; KaufHold, Gewerbelandschaften, S.156; ReEKERS, Beiträge, Teil 5, S.132, 138; Dies., Beiträge, Teil 7, S.128f.

240 In Rheda wurde außerdem Garn gesponnen. Dies., Beiträge, Teil 1, S.136; Dies., Beiträge, Teil 3, S. 59f.; Dies., Beiträge, Teil 6, S. 89f.; Sснамвасн, Stadtbürgertum, S. 18.

241 Reekers, Beiträge, Teil 3, S.33f.; Kaufhold, Gewerbelandschaften, S.164; Hunsche, Landkreis, S.40, 44f. Daneben gab es noch in anderen Gebieten Textilgewerbe mit geringer Bedeutung. So wurden unter anderem in Gimborn-Neustadt, Limburg und Münster Baumwolle und Leinen verarbeitet. Vgl. DösSELER, Wirtschaft, S. 66f.; REEKERS, Beiträge, Teil 1, S.123f.; DiEs., Beiträge, Teil 6, S.78f. 